\title{
GEOENVIROMENTAL EFFECTS OF THE M=6.4 17 NOVEMBER 2015 EARTHQUAKE ON SOUTH LEFKADA, IONIAN SEA, GREECE
}

\author{
Papathanassiou G. ${ }^{1}$, Ganas A. ${ }^{2}$, Moshou A. ${ }^{2}$ and Valkaniotis $\mathrm{S}^{3}$ \\ ${ }^{1}$ Aristotle University of Thessaloniki, gpapatha@geo.auth.gr \\ ${ }^{2}$ National Observatory of Athens, aganas@noa.gr \\ ${ }^{3}$ Koronidos Str., 42100 Trikala, Greece, valkaniotis@yahoo.com
}

\begin{abstract}
The 17th November Mw=6.4 shallow event occurred along a $N 20 \pm 5^{\circ} E$ strike-slip fault with right-lateral sense of slip. The earthquake caused a lot of structural damage to the villages of Agios Petros, Athani, Dragano and Komilio, all located in south Lefkada island. Environmental effects include liquefaction, extensive rock falls and landslides. No surface ruptures were found in the field. Road cracks are interpreted as secondary phenomena of gravitational nature induced by ground shaking. The value of the macroseismic intensity ESI-07 was assessed as VIII-IX. The documentation of the earthquake-induced environmental effects was realized using the Earthquake Geo Survey App. (for Android OS).

Keywords: earthquake, rock falls, liquefaction, Lefkada, 2015.
\end{abstract}

\section{$\Pi \varepsilon \rho i ́ \lambda \eta \psi \eta$}

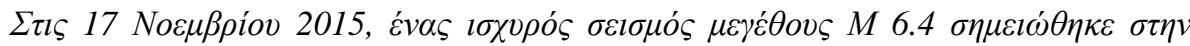

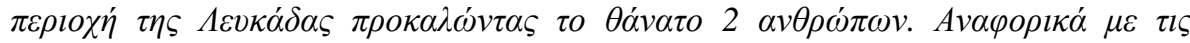

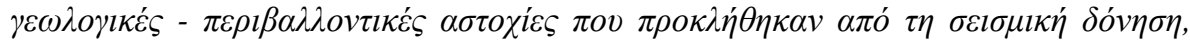

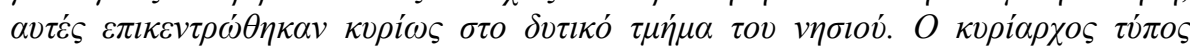

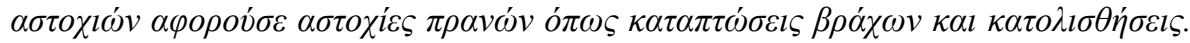

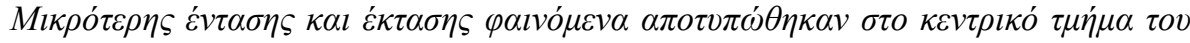

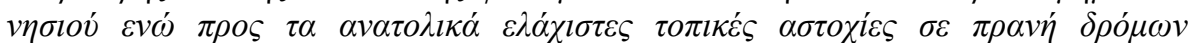

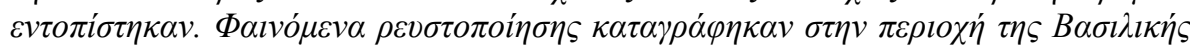

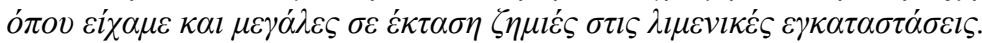

\section{Introduction}

In the morning of November 17, 2015 (09:10 local time) a strong Mw 6.4 shallow earthquake occurred on the island of Lefkada (Ganas et al., 2015). The epicentre determined by the National Observatory of Athens (NOA) was near the village Agios Petros in south Lefkada, with geographic coordinates: $\mathrm{N} 38.666^{\circ}, \mathrm{E} 20.597^{\circ}$ and the depth at $11 \mathrm{~km}$ (Figure 1). The event caused two fatalities while many houses suffered minor damages, mainly situated at villages within the epicentral area. This event occurred 12 years after the last strong 2003 earthquake, near the coast of north Lefkada (Papadopoulos et al., 2003; Karakostas et al., 2004; Papathanassiou et al., 2005; Papadimitriou et al., 2006) and it is the fifth earthquake within one century that triggered severe geoenvironmental effects. 
The goal of this article is to provide information regarding the spatial distribution, and characteristics (incl. dimensions where it was feasible), of the earthquake-induced geological effects. In order to achieve this, this study was based on the outcome of a field survey that took place immediately after the occurrence of the earthquake (Nov 19-22, 2015) and thus, we were able to timely report the triggered geo-environmental effects (slope failures, liquefaction etc.). In the following pages, a detailed map and brief description of the earthquake-induced failures is presented while more information will be published after data processing.

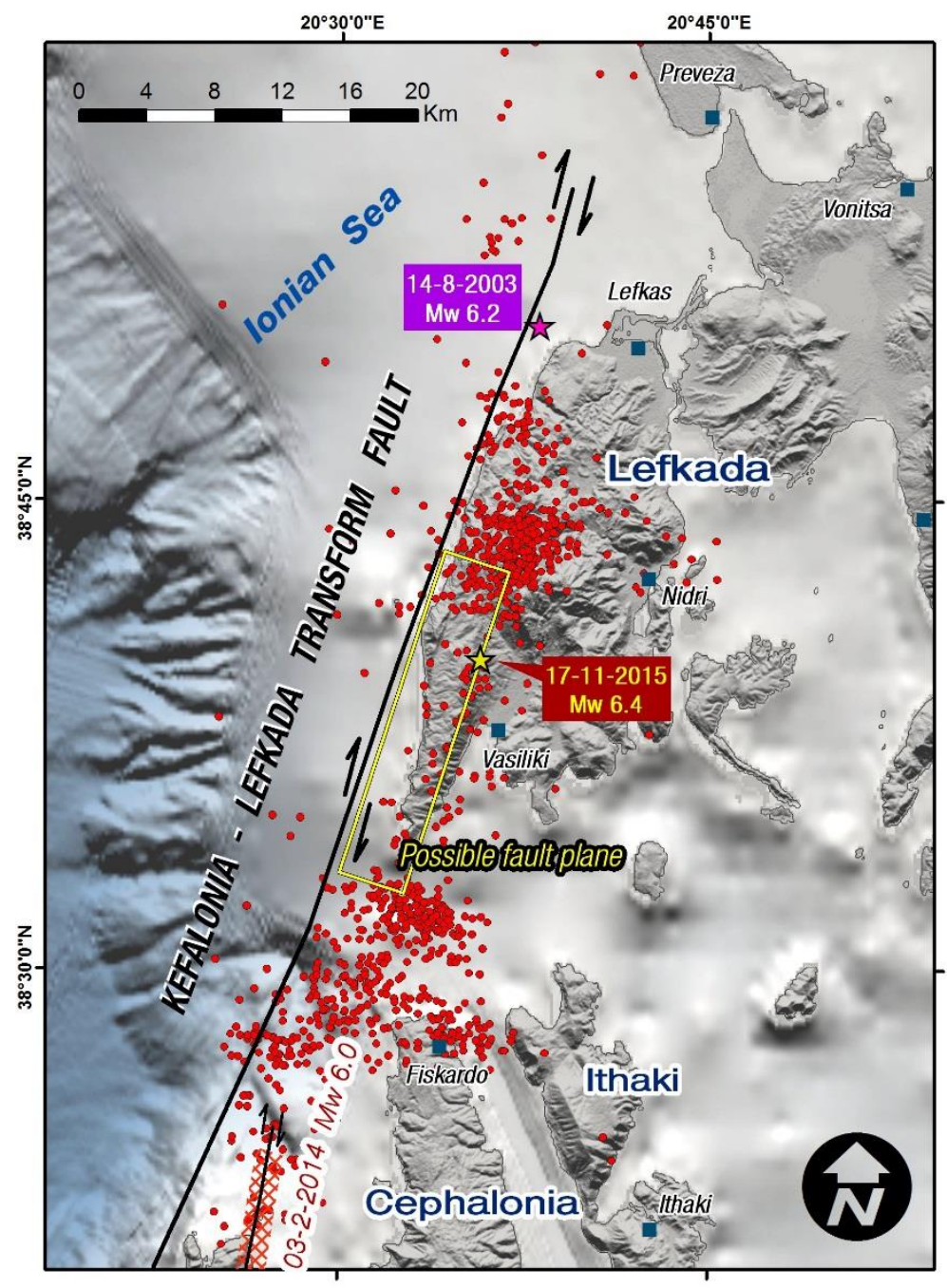

Figure $1-17^{\text {th }}$ November 2015 Lefkada main earthquake and aftershock revised epicentres recorded by National Observatory of Athens (NOA). Dextral faults along the KefaloniaLefkada TF are shown as black lines.

\section{The 17 November 2015 earthquake: location and intensity}

On November 17, 2015, 07:10 GMT (09:10 local time) central Ionian Sea was struck by a strong, shallow earthquake (NOA magnitudes ML 6.0-Mw 6.4 respectively; depth $11 \mathrm{~km}$ ). Based on published Moment Tensor solutions the 2015 earthquake occurred on a near-vertical strike-slip fault running along Lefkada's western coast, with dextral sense of motion in response to ENE-WSW horizontal strain in central Ionian Sea (Ganas et al., 2013). The shallow earthquake ruptured a coastal 
fault, in contrast to the 2014 events that occurred on dextral strike-slip faults onshore Cephalonia (Valkaniotis et al., 2014; Boncori et al., 2015; see Figure 1 for fault surface projection). 1038 revised (NOA) aftershock solutions from the period November 17-December 17, 2015 are plotted in Figures 1 (red dots) and 2 (classified for magnitude and depth). It is evident that a general N-S arrangement of aftershocks exists with two main clusters: one in central Lefkada (Northern cluster) with shallower hypocentres and one in the offshore (mainly) area between Lefkada - Cephalonia (southern cluster). The clusters are possibly formed by Coulomb stress changes on either end of the rupture. According to EPPO-ITSAK the value of PGA recorded at the Vassiliki sensor was equal to $\mathrm{a}=0.36 \mathrm{~g} \quad$ (http://www.itsak.gr/uploads/news/earthquake_reports/Lefkas_M6.0_17-11-2015.pdf/) Taking into account the field observations as they were reported during the post-earthquake reconnaissance survey, the macroseismic intensity was assessed based on the definition of the ESI07 scale. The advantages of the ESI-07 scale is that the assessment of the intensity is solely based on geoenvironmental effects, maintaining the consistency with the historical seismicity and the relevant provided information, and accordingly the man made environment e.g. seismic codes cannot influence the final assessment of the macroseismic intensity (Papathanassiou and Pavlides, 2007). As a preliminary outcome, it is concluded that the highest intensity was observed within the area delineated by the villages of Dragano - Athani - Porto Katsiki and Egremnoi beach.

\section{Historical seismicity}

The Ionian Islands have suffered from many destructive earthquakes. There is reliable, semi-detailed information for at least twenty four (24) events, since 1612 which induced ground failures at the island of Lefkada (Kouskouna et al., 1993; Papathanassiou et al., 2005). Regarding the similarity of earthquake-induced failures among these events, it can be concluded that four, 1783, 1885, 1914 and April 1948 events triggered similar failures with the ones generated by the 2015 event.

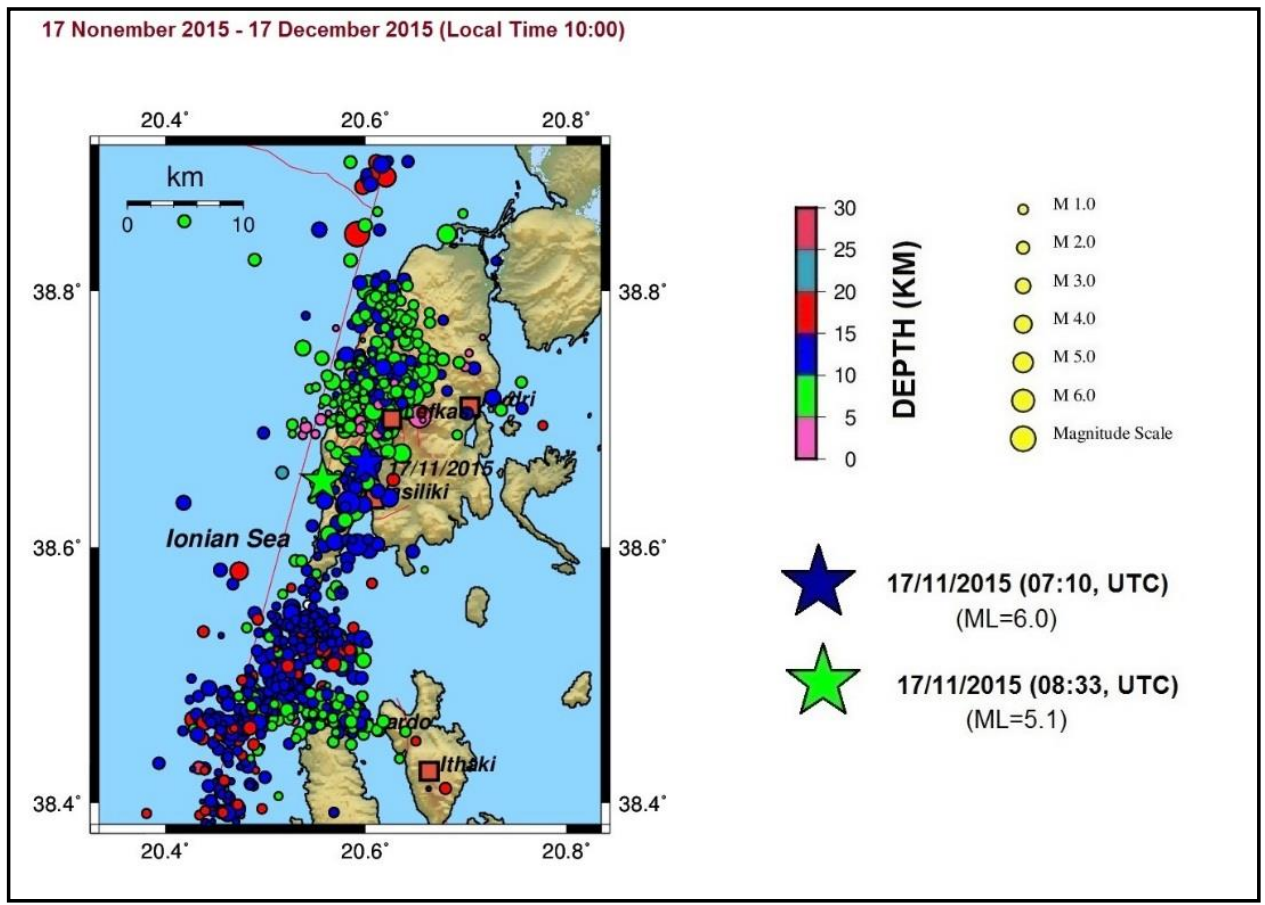

Figure 2 - Seismicity map of the Lefkada sequence from NOA analysis (revised) data. Map contains 1038 shallow events until December $17^{\text {th }}, 2015$. 


\section{Geoenvironmental effects}

The majority of earthquake-related phenomena were rock falls, landslides, road-fill failures and small-scale size liquefaction (Figure 3). The area that was widely affected by these phenomena is the one delineated by the villages of Komilio, Dragano and Athani on the east and to the west by the coastal zone from Porto Katsiki to Ag. Nikitas (Figure 3). This zone is characterized as very likely to slope failures due to the combination of geomorphological parameters (high elevation and steep slope) with the highly fracture rock mass due to tectonic activity (Papathanassiou et al., 2005). Regarding the eastern part of the island, the earthquake triggered only sparse and small size rock falls on very prone to slope failures sites e.g. road cuts while at the northern part of the island, where the city of Lefkada is located, no geoenvironmental effects have been reported.

The documentation of the earthquake-induced environmental effects was realized using the Earthquake Geo Survey App. (for Android OS).

\subsection{Slope failures}

The dominant geoenvironmental effects triggered by the 2015 Lefkada earthquake were related to slope failures. Rock falls and landslides were widespread on the western part of the island and at the central area, on both natural and cut slopes. The most densely concentration of these type of earthquake-induced ground deformations was reported on the coastal zone from Porto Katsiki to Egremnoi beach and along the $6 \mathrm{~km}$ long road of Tsoukalades- Ag. Nikitas, and are accompanied by small and large-size rock falls, rock mass slides and shallow landslides. It should be pointed out that this zone has been classified as very susceptible to slope failures by Papathanassiou et al. (2013).

Furthermore, cracks on paved roads were observed along the road network at the central and western part of the island, mainly within the zone that has been previously mentioned. One of the most representative cases of this type of failure has been observed at the entrance of village Athani, resulted to the closure of this road.

\subsection{Liquefaction phenomena}

Although the fact that event is characterized as one of the strongest shocks that occurred in the island of Lefkada, generation of liquefaction-induced ground failures were mainly concentrated along the coastal zone between the villages of Vassiliki and Ponti. In particular, spots of small-scale liquefaction features e.g. sand craters and a ground crack through which grey fine-grained material was ejected were reported. In addition, the 2015 earthquake induced severe damages to the waterfront area of Vassiliki and particularly to the recently constructed pier and quay. It should be pointed out that no evidence of liquefaction, like ejecta through the cracks, was observed.

\section{Environmental Seismic Intensity scale ESI-07}

One of the goals of the post-earthquake field survey was to quantitatively report the earthquakeinduced ground failures in order to proceed to the assessment of the macroseismic intensity. In order to achieve this, we applied the Environmental Seismic Intensity scale ESI-07 (Michetti et al., 2007). As a preliminary outcome, it can be concluded that the highest intensity was observed within the area delineated by the villages of Dragano - Athani - Porto Katsiki and Egremnoi beach. The value of the macroseismic intensity ESI-07 within this zone was assessed as VIII-IX. 


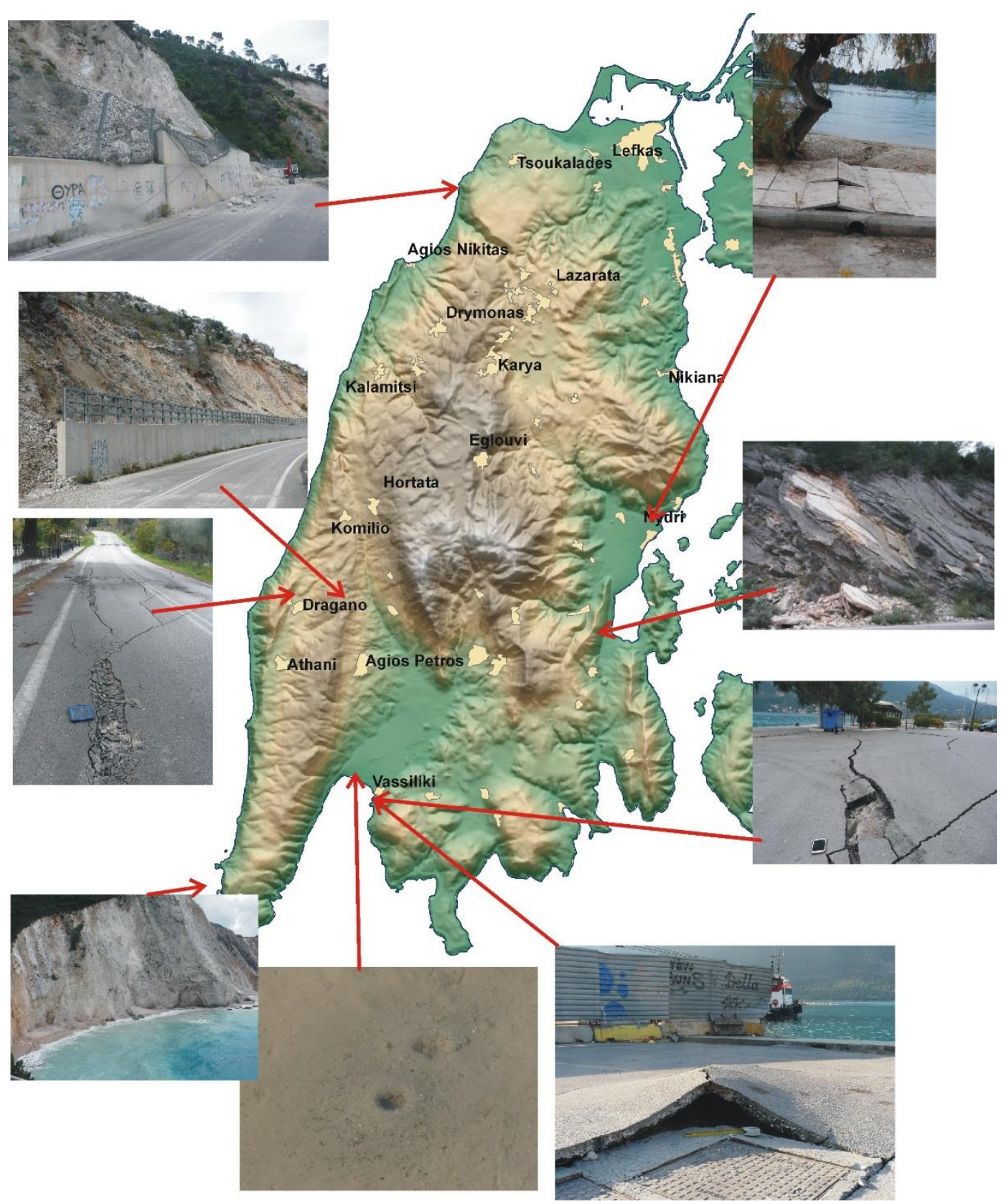

Figure 3 - Spatial distribution of earthquake-induced failures triggered by the Lefkada 2015 event. See text for discussion.

\section{Acknowledgments}

We thank the NOA seismic data analysis team for phase data. We also thank Efthimios Lekkas, Iannis Koukouvelas, Efthimios Sokos, Yiannis Kassaras, Vassilis Karakostas, Panagiotis Paschos, Pierre Briole, George Bozionelos, Antonio Avallone, Diego Melgar, Panagiotis Argyrakis, 
Evangelos Mendonidis, Panagiotis Elias, Fillippos Doukatas and Spiros Pavlides for discussions. Fieldwork was funded by the GSRT project INDES-MUSA http://www.indes-musa.gr/.

\section{References}

Boncori, M., Papoutsis, I., Pezzo, G., Tolomei, C., Atzori, S., Ganas, A., Karastathis, V., Salvi, S., Kontoes, Ch. and Antonioli, A., 2015. The February 2014 Cephalonia earthquake (Greece): 3D deformation field and source modeling from multiple SAR techniques, Seismological Research Letters, January/February 2015, 86(1), 124-137. http://dx.doi. org/10.1785/0220140126 (First published on November 19, 2014).

Ganas, A., Marinou, A., Anastasiou, D., Paradissis, D., Papazissi, K., Tzavaras, P. and Drakatos, G., (2013). GPS-derived estimates of crustal deformation in the central and north Ionian Sea, Greece: 3-yr results from NOANET continuous network data, Journal of Geodynamics, 67, 62-71.

Ganas, A., Briole, P., Papathanassiou, G., Bozionelos, G., Avallone, A., Melgar, D., Argyrakis, P., Valkaniotis, S., Mendonidis, E., Moshou, A. and Panagiotis, E., 2015. A preliminary report on the Nov 17, 2015 M=6.4 South Lefkada earthquake, Ionian Sea, Greece, Released on Dec. 4th to EMSC, http://www.emsc-csem.org/Earthquake/239/M6-5-GREECE-on-November17th-2015-at-07-10-UTC/.

Karakostas, V., Papadimitriou, E. and Papazachos, C., 2004. Properties of the 2003 Lefkada, Ionian Islands, Greece, earthquake seismic sequence and seismicity triggering, Bull. Seismol. Soc. Am. 94, 1976-1981.

Kouskouna, V., Makropoulos, K.C. and Tsiknakis, K., 1993. Contribution of historical information to a realistic seismicity and hazard assessment of an area, The Ionian Islands earthquakes of 1767 and 1769: historical investigation. In: Stucchi, M., ed., "Historical Investigation of European Earthquakes," Materials of the CEC project "Review of Historical Seismicity in Europe", 1, 195-206.

Michetti, A.M., Esposito, E., Guerrieri, L., Porfido, S., Serva, L., Tatevossian, R., Vittori, E., Audemard, F., Azuma, T., Clague, J., Comerci, V., Gurpinar, A., McCalpin, J., Mohammadioun, B., Morner, N.A., Ota, Y. and Roghozin, E., 2007. Intensity Scale ESI (2007). In: Memorie Descrittive Carta Geologica d'Italia, Guerrieri, L. and Vittori E. ed., APAT, Servizio Geologico d'Italia-Dipartimento Difesa del Suolo, Roma, Italy, 74, 53 pp.

Papadimitriou, P., Kaviris, G. and Makropoulos, K., 2006. The Mw=6.3 2003 Lefkada Earthquake (Greece) and induced transfer changes, Tectonophysics, 423, 73-82.

Papadopoulos, G.A., Karastathis, V.K., Ganas, A., Pavlides, S., Fokaefs, A. and Orfanogiannaki, K., 2003. The Lefkada, Ionian Sea (Greece), shock (Mw 6.2) of 14 August 2003: Evidence for the characteristic earthquake from seismicity and ground failures, Earth Planet, Space, 55, 713-718.

Papathanassiou, G., Pavlides, Sp. and Ganas, A., 2005. The 2003 Lefkada earthquake: Field observations and preliminary microzonation map based on liquefaction potential index for the town of Lefkada, Engineering Geology, 82, 1, 12-31.

Papathanassiou, G. and Pavlides, S., 2007. Using the INQUA scale for the assessment of intensity: Case study of the 2003 Lefkada (Ionian Islands), Greece earthquake, Quaternary International, 173-174, 4-14.

Papathanassiou, G., Valkaniotis, S., Ganas, A. and Pavlides, S., 2013. GIS-based statistical analysis of the spatial distribution of earthquake-induced landslides in the island of Lefkada, Ionian Islands, Greece, Landslides, 10, 6, 771-783,doi:10.1007/s10346-012-0357S.

Valkaniotis, S., Ganas, A., Papathanassiou, G. and Papanikolaou, M., 2014. Field observations of geological effects triggered by the January-February 2014 Cephalonia (Ionian Sea, Greece) earthquakes, Tectonophysics, 630, 150-157. 


\title{
ESI-2007. A NEW MACROSEISMIC ENVIRONMENTAL SEISMIC INTENSITY SCALE ORIENTED ON GEOLOGICAL DEFORMATIONS
}

\author{
Papathanassiou G. and Pavlides S. \\ Aristotle University of Thessaloniki, School of Geology, 54124, Thessaloniki, Greece, \\ gpapatha@auth.gr,pavlides@geo.auth.gr
}

\begin{abstract}
Intensity scales are used in order to measure the effects of an earthquake using the impact of the ground shaking on humans, man made environment and environment. The ESI-2007 is a new scale based solely on the earthquake-induced ground deformations, proposed by the INQUA Subcommission on Paleoseismicity. This scale has been translated in seven languages for a more systematic application. In this review article the new Intensity Scale is presented, as well as a brief of the earthquake case studies, occurred in Greece recently, in which the ESI-2007 was applied, is taken place. In addition, the definitions of intensity degrees are provided in Greek at the end of this article as appendix.
\end{abstract}

Keywords: Earthquake Intensity, ground deformation effects, seismicity of Greece.

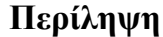

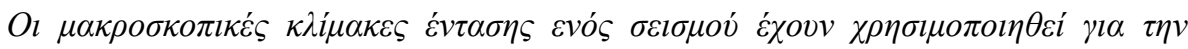

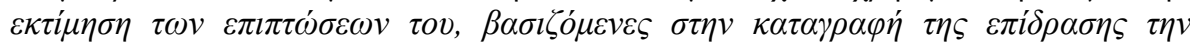

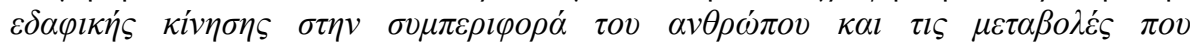

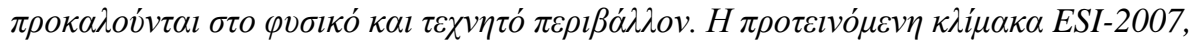

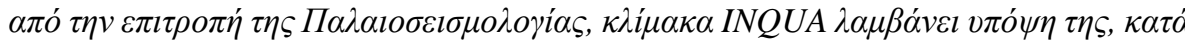

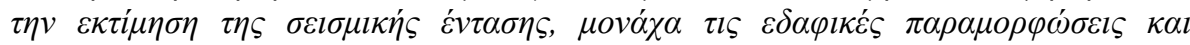

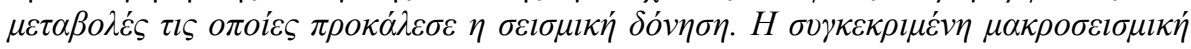

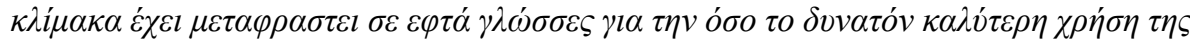

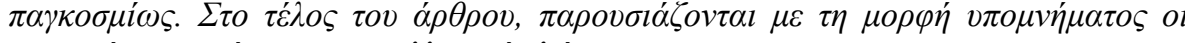

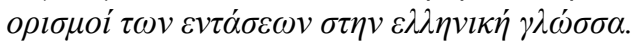

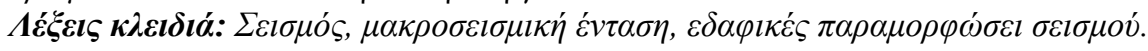

\section{Introduction}

Seismic intensity is used to estimate the level of the ground shaking based on descriptions of the effects that were triggered by the earthquake. In countries with well documented reports concerning historical seismicity e.g. Greece, the distribution of the intensity can help scientists to estimate the locations and sizes of earthquakes that occurred before the instrumental period, and thus assess the seismic hazard of the area.

For the evaluation of intensity, the three parameters of reported ground failures, structural damage, and peoples' reactions should be taken into account at the same weight. However, the EMS (European Macroseismic Scale) scale seems to underestimate the earthquake-induced ground effects. The evaluated intensities based on EMS scale mainly depend on the vulnerability of 
buildings. However, building performance depends on the seismic code provisions of each country. For example, Greece has updated the code several times since 1959. Obviously, the vulnerability of the buildings that were constructed based on the guidelines of the upgraded versions is reduced relative to the buildings constructed before 1959. This situation could lead to a different estimate of the size of an earthquake that occurred in two regions where the building stock is comprised of old and modern structures, respectively. Furthermore, there is a possibility of error when comparing the intensities of recent and past events, creating an error in the assessment of the seismic hazard analysis of the region.

In order to avoid this inaccuracy, a scale based solely on earthquake environmental effects that can be used in combination with other scales was developed by the INQUA (Intenational Quaternary Association), Subcommission on Paleoseismicity. The recently Environmental Seismic Intensity scale (ESI 2007) described by Michetti et al. (2007), is the result of the revisions of previous versions. In addition, in order to facilitate the worldwide use of the ESI 2007 scale, it has been translated in ten lan. Moreover, an application for Android systems was developed by Papathanassiou and Kopsachilis in 2013 based on the Earthquake Environmental Effects form, proposed by the INQUA TERPRO Focus Area on Paleoseismology and Active Tectonics, for reporting earthquake-induced deformations and processing the collected data at the end of a post-earthquake reconnaissance field survey. This application, named Earthquake Geo Survey, can be installed both in tablets and smart phones.

More information about the INQUA scale and the definitions of intensity degrees can be found on the website http://www.isprambiente.gov.it/en/publications/technical-periodicals/descriptivememories-of-the-geological-map-of/earthquake-environmental-effect-for-seismic-hazardassessment-the-esi-intensity-scale-and-the-eee-catalogue.

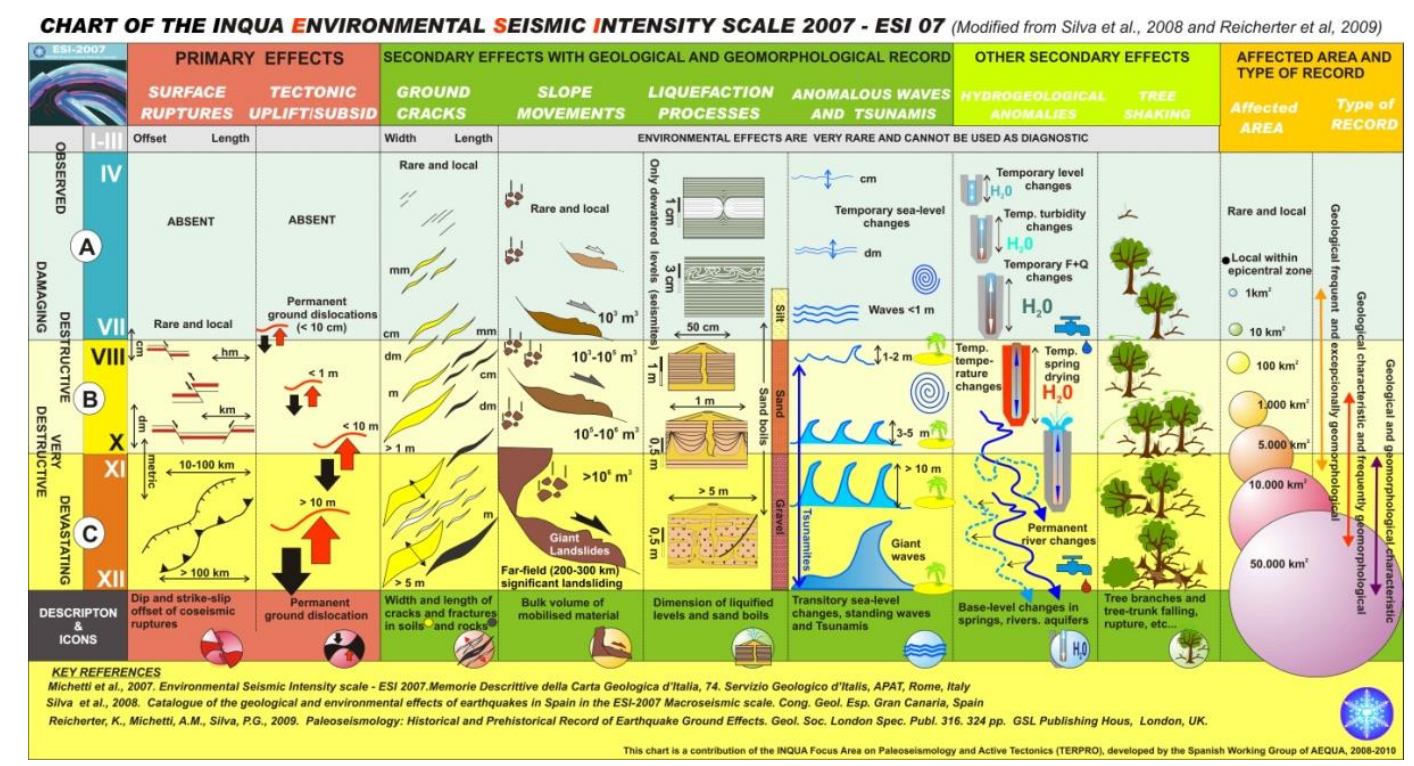

Figure 1 - Chart of the ESI-2007 scale (Michetti et al., 2007).

\section{Applying the ESI-2007 in Greece}

The ESI-2007 scale has been applied in several earthquake case studies in Greece e.g. Lefkada 2003, Athens 1999, Kythira 2006 in order to evaluate the macroseismic intensity values. A brief summary of the studies performed for these events is provided below. In particular:

The Lefkada 2003 earthquake (Papathanassiou and Pavlides, 2007)

From the comparison among the evaluated intensities of the Lefkada 2003 earthquake based on the ESI-2007 scale and the EMS scale (Papadopoulos et al., 2003), it was concluded that in most of the 
sites the values are about the same. However, significant differences are concentrated in villages that have been constructed after the revision of the first Greek seismic code (1992), where the strengthening of the buildings resulting in better performance under ground shaking. At these sites the evaluated intensities based on EMS scale are lower than the "INQUA intensity" degrees, due to the fact that the evaluation of the EMS intensity is mainly based on building performance. At these locations, differences are also observed among the intensity degrees of two past events (1914 Ms 6.3 and 1948 Ms 6.5) and the values of the last one based on the EMS scale, although the ground failures are similar. At these sites the evaluated INQUA degrees are more similar to the intensities of the previous events, than are the EMS ones, helping comparison of the historical seismicity with recent seismic activity.

Sofades 1954 (Papathanassiou et al., 2007)

The Sofades 1954 earthquake (Ms 6.8) induced severe structural damages and remarkable environmental effects in an extended area of Central Greece. The maximum intensity, based on ESI2007 scale, was evaluated as IX-X at the site of Ekkara, where surface faulting was reported. At the other locations, the degrees of intensities range from VI to VIII. From the comparison of the "ESI2007" values of intensities with the "MM" ones, as they were assessed by Papazachos and Papazachou (1989), is concluded that at sites where the event induced severe secondary effects the evaluated intensities are about the same. However, at the site of Sofades the degree of intensity based on MM scale was evaluated as IX-X due to structural damages, although no ground deformations were reported.

Alkyonides 1981 (Papanikolaou et al., 2009)

In the 1981 Alkyonides example, the ESI 2007 intensity scale provides not only a slightly higher maximum epicentral intensity $(\mathrm{X})$, but also a different spatial distribution of the isoseismals, compared to the traditional scales. This implies that current traditional scales possibly underestimate the 'strength' of this kind of earthquake sequence. This occurs partly because the epicentral area, where significant EEE were recorded, was relatively sparsely populated.

Elia 1988 (Fokaefs and Papadopoulos, 2007)

The evaluated intensities based on ESI scale are as high as those resulting from the Modified Mercalli scale. This is because the Elia 1988 earthquake triggered widespread environmental effects including cracks, rock falls and liquefaction and accordingly both the MM and ESI scale intensities were based on similar effects.

Pyrgos 1993 (Papanikolaou et al., 2009)

The EMS 1992 and the ESI 2007 scales seem to comply well regarding not only the maximum recorded epicentral intensity, but also with the overall isoseismal pattern. Nevertheless, it should be mentioned that no villages were founded near the landslide or the liquefaction-prone areas, otherwise it is possible that the traditional intensities would have recorded a higher epicentral intensity value.

Athens 1999 (Fokaefs and Papadopoulos, 2007)

Regarding the evaluated intensities for this event, Fokaefs and Papadopoulos (2007) concluded that the ESI-based ones failed to approach the MM intensities due to the fact that there were only few ground failures. Because of this ESI-based intensities are much lower than those assessed using the MM intensity scale.

Kythira 2006 (Lekkas et al., 2008)

Regarding the 2006 Kythira event, the ESI 2007 and the traditional macroseismic scales correlate well, suggesting a maximum VII-VIII intensity.

\section{Conclusion - Discussion}

Taking into account the fact that the ESI-2007 scale has been applied in a wide variety of earthquakes regarding the magnitude and the generation of geological failures, we believed that a summary 
dealing with the reliability and accuracy of the evaluated intensities could be provided. This outcome, summarized by the previously mentioned studies, is briefly presented below:

- In case of earthquakes-induced ground deformations, the application of the new macroseismic intensity scale (ESI-2007) results to similar degrees of intensity as the MM scale. However, in an absence or low severity ground damage, ESI-scale intensities may underestimate the overall effects of an earthquake.

- On the contrary in urban areas constructed according to modern code provisions, the evaluation of the intensity based on EMS scale may underestimate the ground shaking

- There is inconsistency between ESI 2007 and traditional scales for the high intensity values (IX, $\mathrm{X})$. In particular, the "saturation" of the traditional scales at these values indicates the meaningful of the ESI-2007.

- When the ESI 2007 and the traditional intensity scales disagree, the intensity has to coincide with the highest value between these two independent estimates (Papanikolaou et al., 2009)

- Earthquake environmental effects provide higher objectivity in the process of assigning intensity values, so that the ESI 2007 scale is the best tool to compare recent, historic and pre-historic earthquakes as well as earthquakes from different tectonic settings (Papanikolaou et al., 2009)

\section{References}

Fokaefs, A. and Papadopoulos, G., 2007. Testing the New INQUA Intensity Scale in Greek Earthquakes, Quaternary International, 173/174, 15-22.

Lekkas, E.L., Papanikolaou, I.D., Papanikolaou, D.I. and Danamos, G., 2008. Correlating the damage pattern and the geological structure. Local site effects from the $2006 \mathrm{MW}=6.7$ KYTHIRA island intermediate depth event, SW Greece, The 14th World Conference on Earthquake Engineering October 1217, 2008, Beijing, China.

Michetti, A.M., Esposito, E., Guerrieri, L., Porfido, S., Serva, L., Tatevossian, R., Vittori, E., Audemard, F., Azuma, T., Clague, J., Comerci, V., Gurpinar, A., McCalpin, J., Mohammadioun, B., Morner, N.A., Ota, Y. and Roghozin, E., 2007. Environmental Seismic Intensity Scale 2007, ESI 2007. In: Guerrieri, L. and Vittori, E., eds., Intensity Scale ESI 2007, Memorie descrittive della Carta Geologica d' Italia, 74, 7-54.

Papadopoulos, A.G., Karastathis, V., Ganas, A., Pavlides, S., Fokaefs, A. and Orfanogiannaki, K., 2003. The Lefkada, Ionian Sea (Greece), shock (Mw 6.2) of 14 August 2003: evidence for the characteristic earthquake from seismicity and ground failures, Earth Planets and Space, 55, 713-718.

Papanikolaou, I.D., Papanikolaou, D.I. and Lekkas, E.L., 2009. Advances and limitations of the Environmental Seismic Intensity scale (ESI 2007) regarding near-field and farfield effects from recent earthquakes in Greece: implications for the seismic hazard assessment. In: Reicherter, K., Michetti, A.M. and Silva Barroso, P.G., eds., Palaeoseismology: Historical and Prehistorical Records of Earthquake Ground Effects for Seismic Hazard Assessment, The Geological Society, London, Special Publ., 316, 1130.

Papathanassiou, G. and Pavlides, S., 2007. Using the INQUA Scale for the Assessment of Intensity: Case Study of the 2003 Lefkada (Ionian Islands), Greece Earthquake, Quaternary International, 173-174, 4-14.

Papathanassiou, G., Valkaniotis, S. and Pavlides, S., 2007. Applying the INQUA scale to the Sofades 1954, central Greece, earthquake, Proc. of the 11th International Conference of Greek Geological Society, Bulletin of the Geological Society of Greece, XXXVII, 1226-1233.

Papazachos, B.C. and Papazachou, K., 1989. The earthquakes of Greece, Ziti Publ., Thessaloniki, 365 pp. 


\section{Appendix}

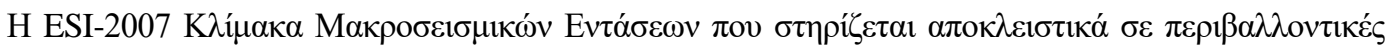

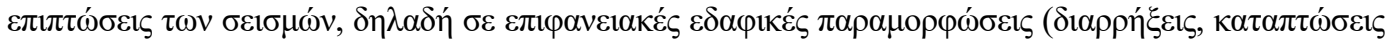

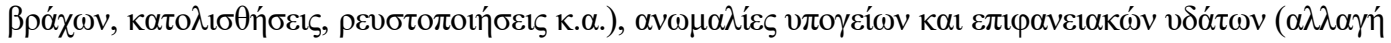

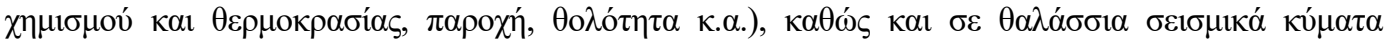

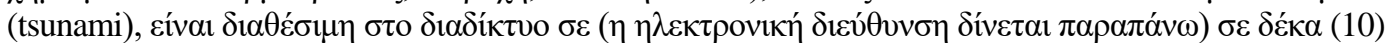

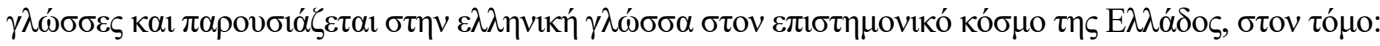

Earthquake Environmental Effects for seismic hazard Assessment: the ESI intensity scale and the EEE Catalogue, Memorie, Carta Geologica D'Italia, ISPRA, Servizio Geologico D'Italia, XCVII, 181 pp.

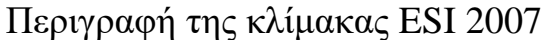

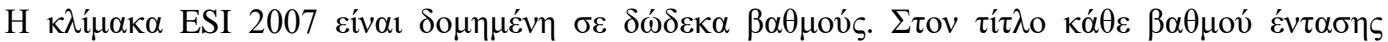

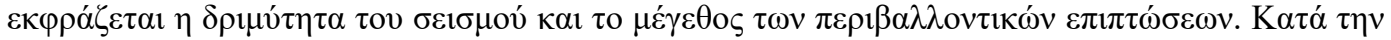

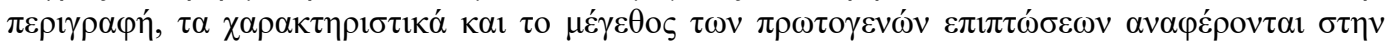

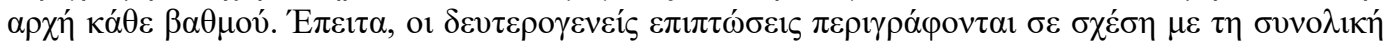

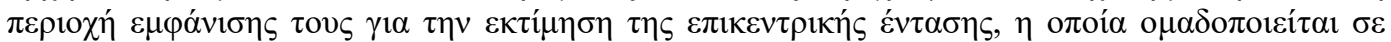

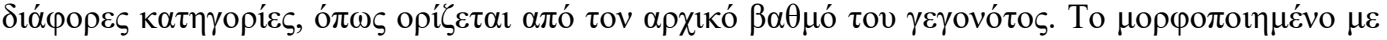

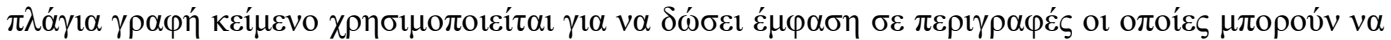

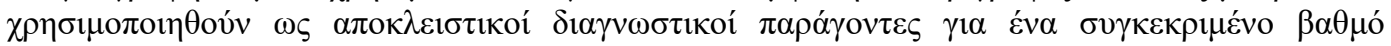
$\varepsilon \dot{v} \tau \alpha \sigma \eta \varsigma$

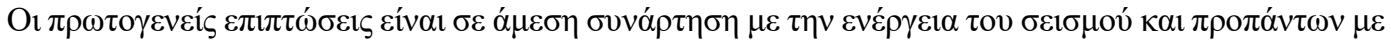

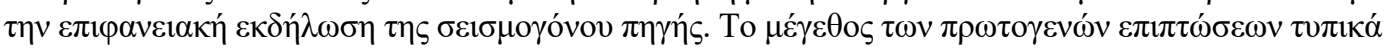

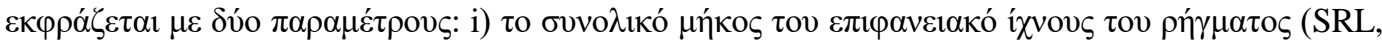

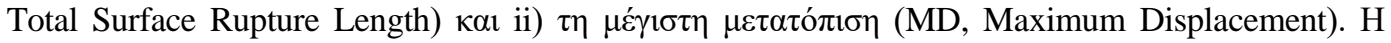

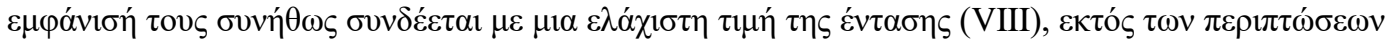

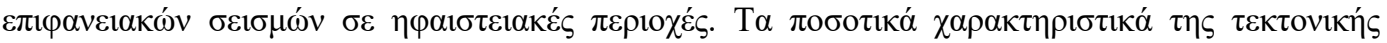

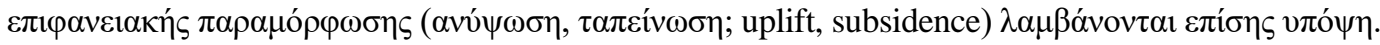

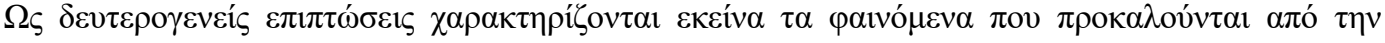

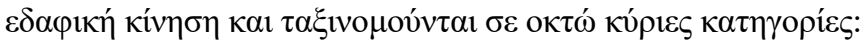

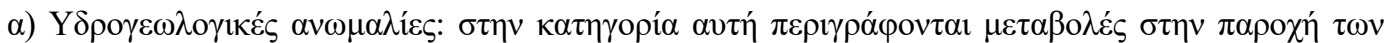

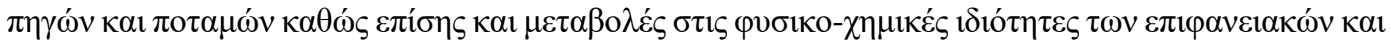

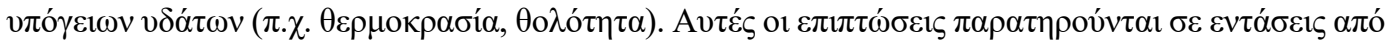
IV $\varepsilon ́ \omega \varsigma$ X.

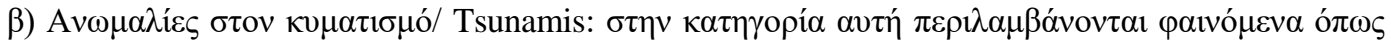

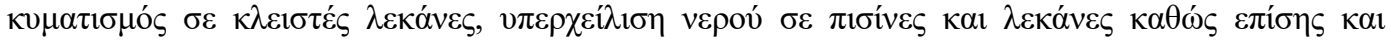

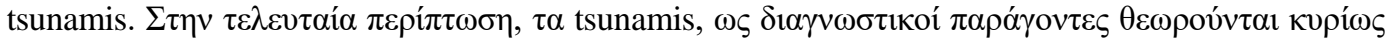

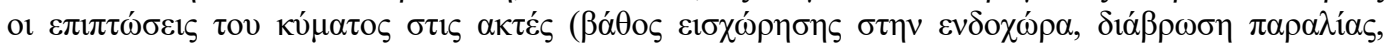

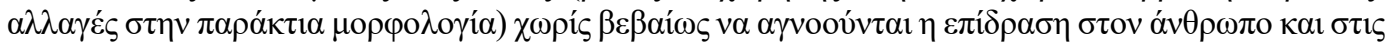
$\kappa \alpha \tau \alpha \sigma \kappa \varepsilon v \varepsilon ́ \zeta$.

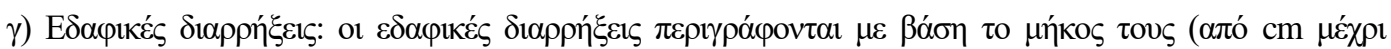

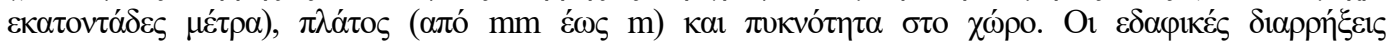

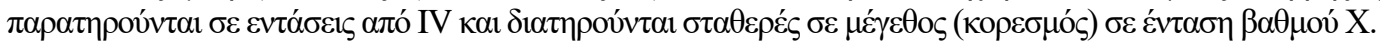

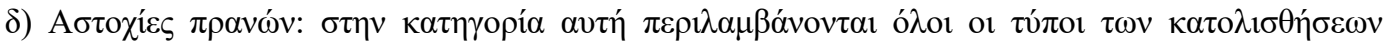

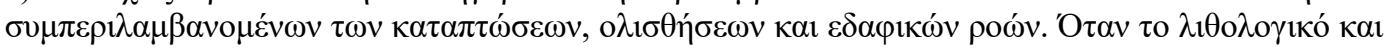

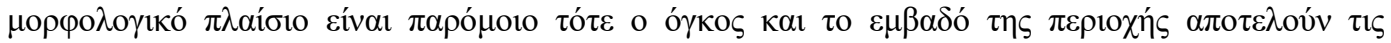

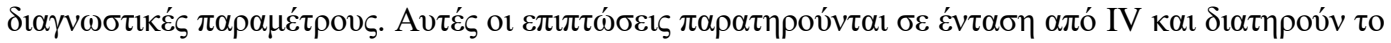

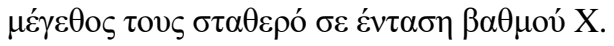




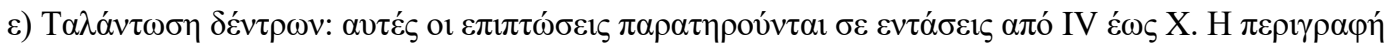

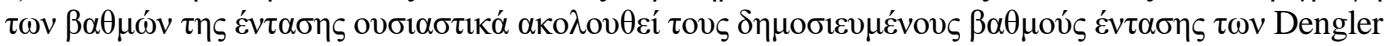

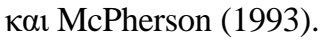

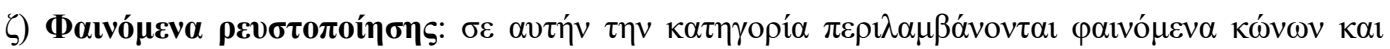

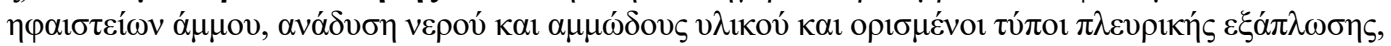

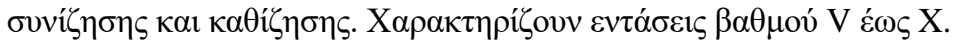

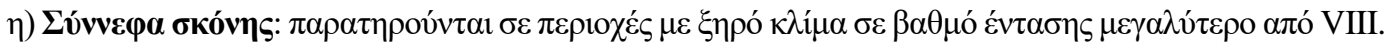

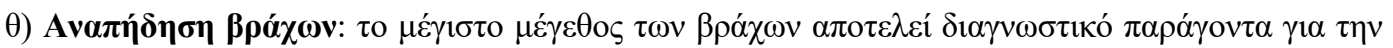

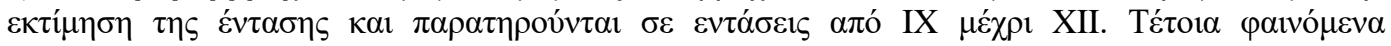

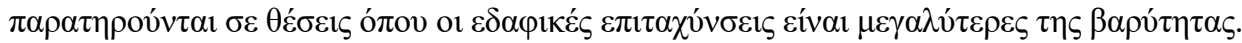

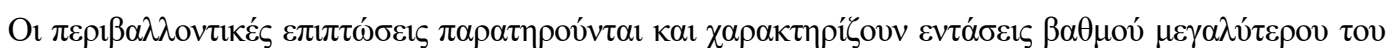

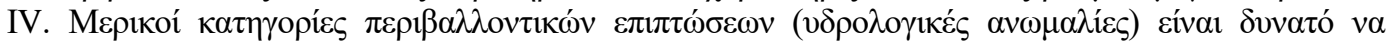

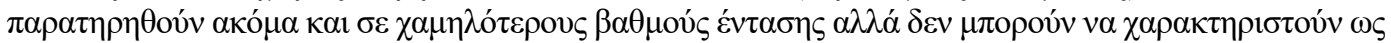

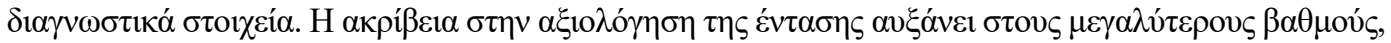

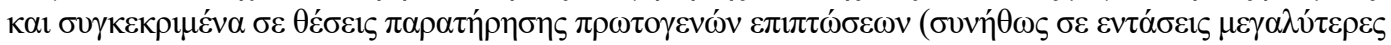

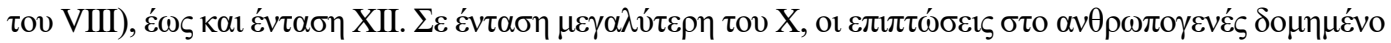

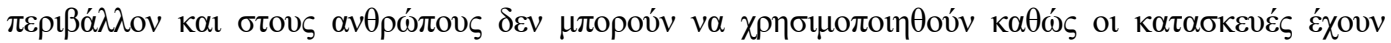

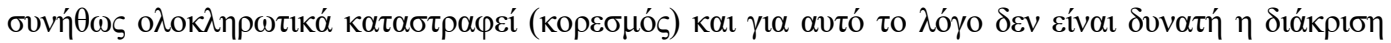

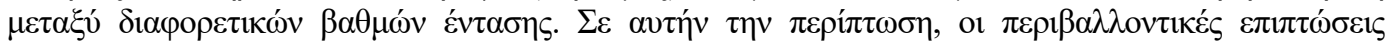

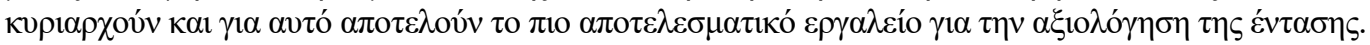

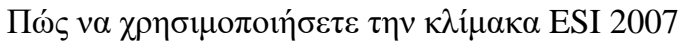

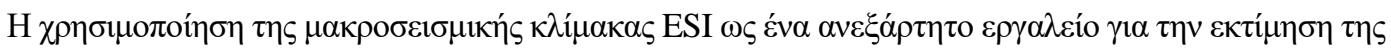

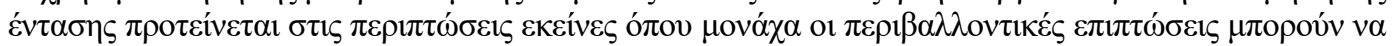

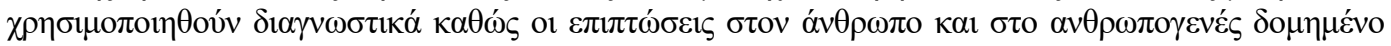

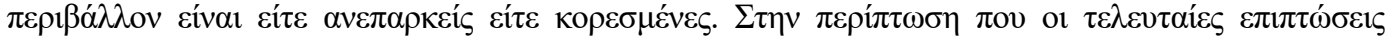

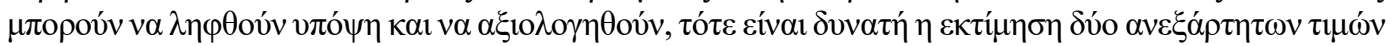

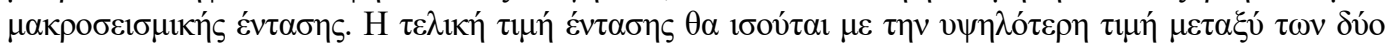

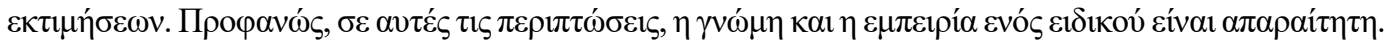

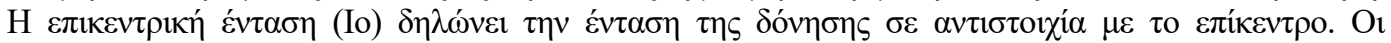

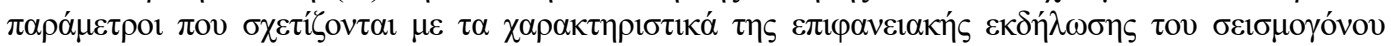

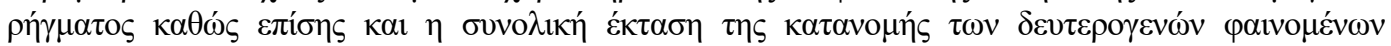

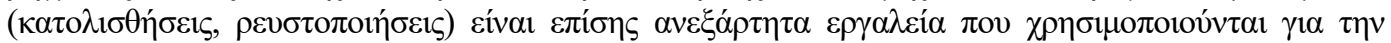

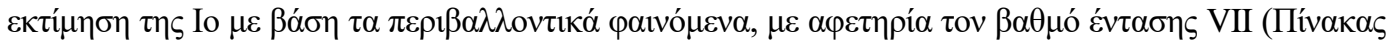

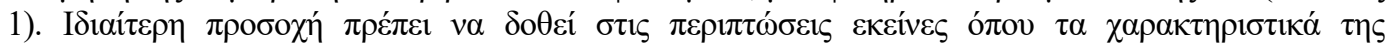

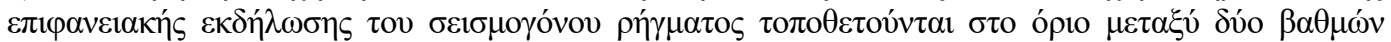

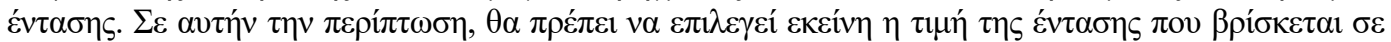

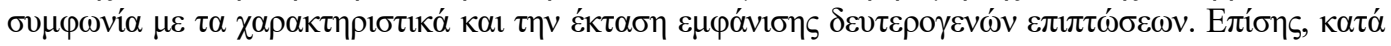

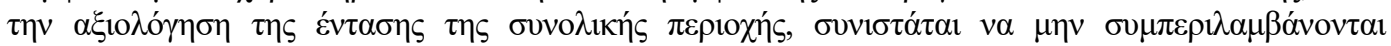

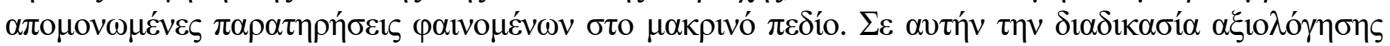

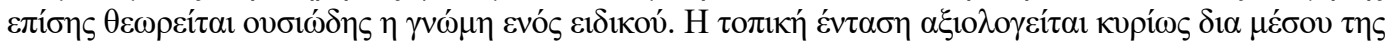

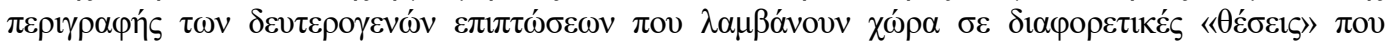

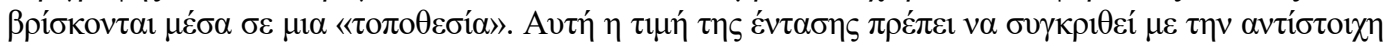

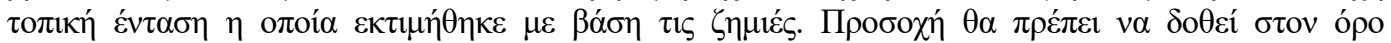

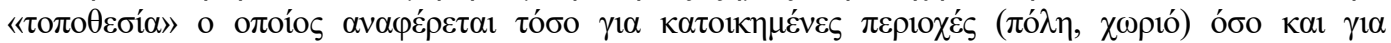

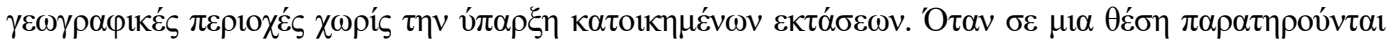

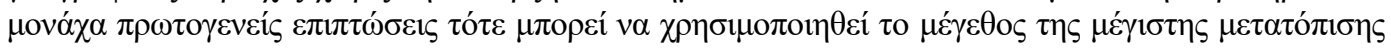

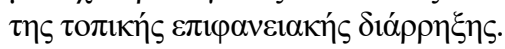




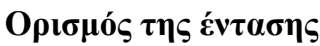

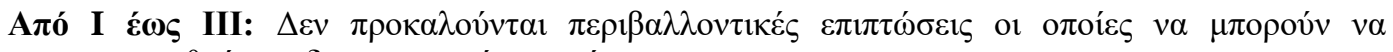

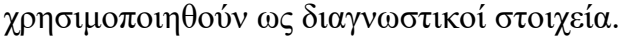

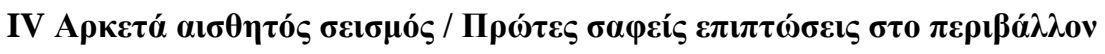

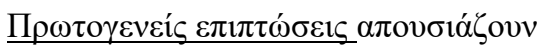

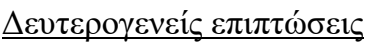

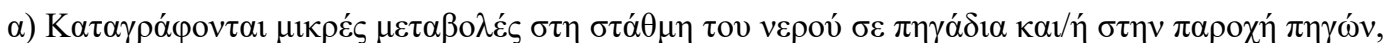

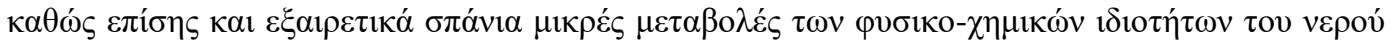

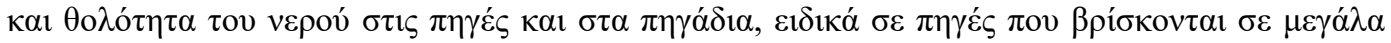

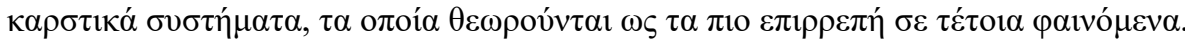

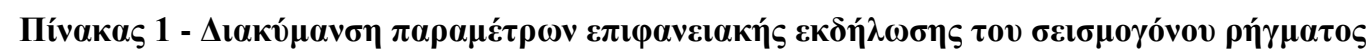

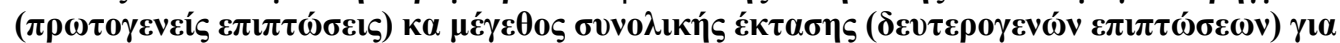

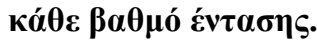

\begin{tabular}{|c|c|c|c|}
\hline \multirow{2}{*}{$\mathbf{I}_{\mathbf{0}}$} & \multicolumn{2}{|c|}{ 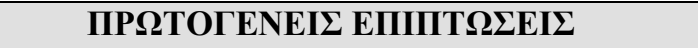 } & \multirow{2}{*}{ 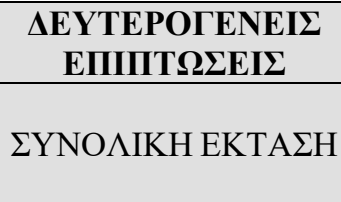 } \\
\hline & $\begin{array}{c}\text { MHKO } \Sigma \\
\text { ЕПIФANEIAKH } \Sigma \\
\triangle \mathrm{IAPPH \Xi H \Sigma}(\mathrm{SRL})\end{array}$ & 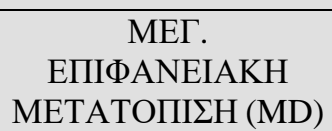 & \\
\hline IV & - & - & - \\
\hline $\mathbf{V}$ & - & - & - \\
\hline VI & & - & - \\
\hline VII & $(*)$ & $(*)$ & $10 \mathrm{~km}^{2}$ \\
\hline VIII & 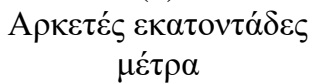 & $\varepsilon \kappa \alpha \tau о \sigma \tau o ́ \mu \varepsilon \tau \rho \alpha$ & $100 \mathrm{~km}^{2}$ \\
\hline IX & $1-10 \mathrm{~km}$ & $5-40 \mathrm{~cm}$ & $1000 \mathrm{~km}^{2}$ \\
\hline $\mathbf{X}$ & $10-60 \mathrm{~km}$ & $40-300 \mathrm{~cm}$ & $5000 \mathrm{~km}^{2}$ \\
\hline $\mathbf{X I}$ & $60-150 \mathrm{~km}$ & $300-700 \mathrm{~cm}$ & $10000 \mathrm{~km}^{2}$ \\
\hline XII & $>150 \mathrm{~km}$ & $>700 \mathrm{~cm}$ & $>50000 \mathrm{~km}^{2}$ \\
\hline
\end{tabular}

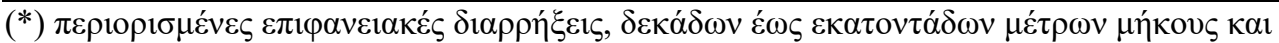

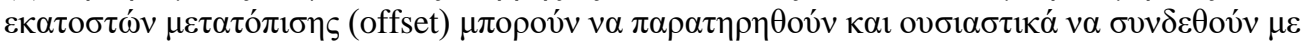

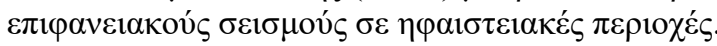

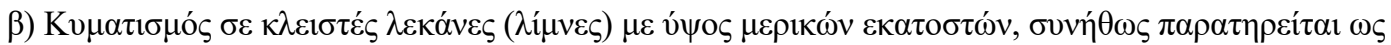

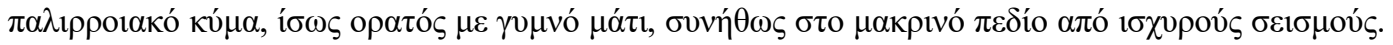

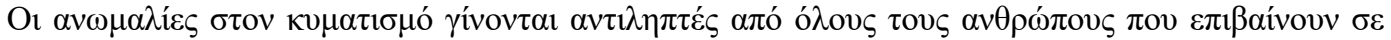

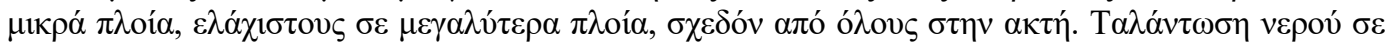

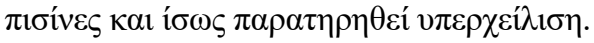

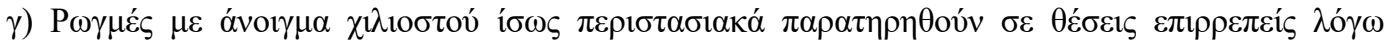

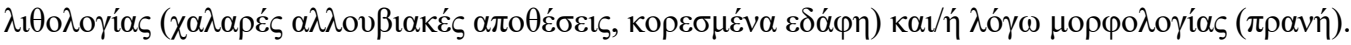

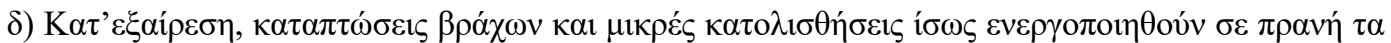

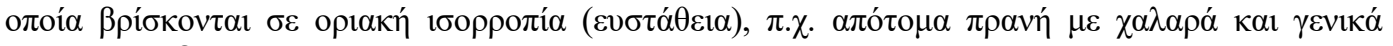

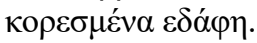

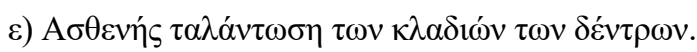

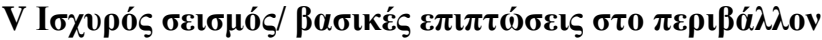

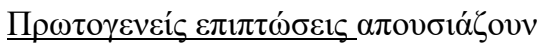

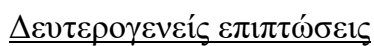




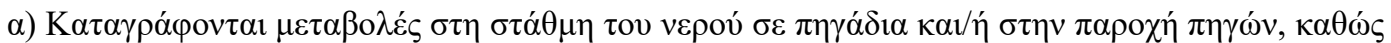

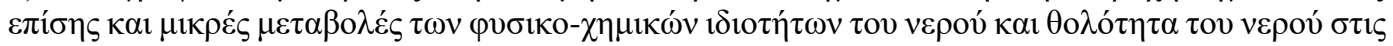

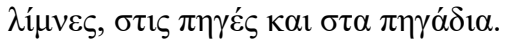

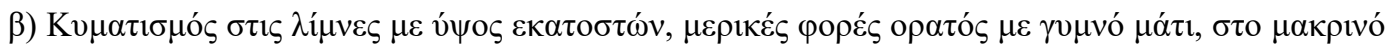

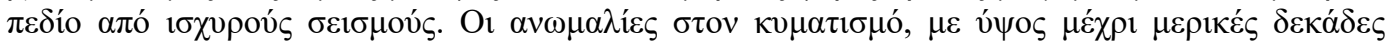

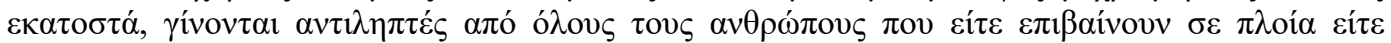

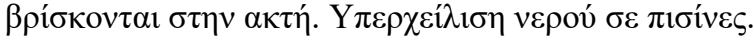

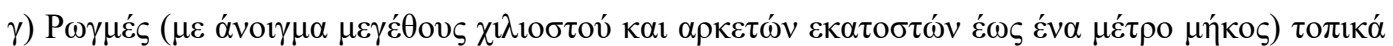

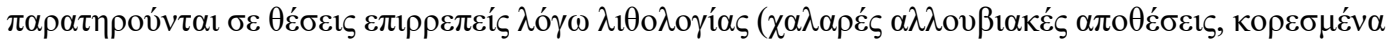

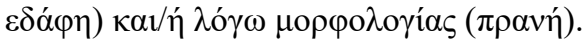

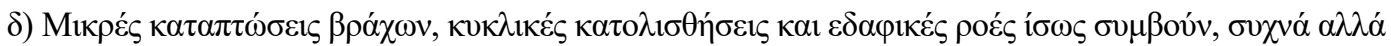

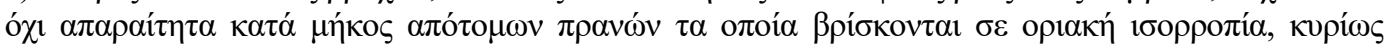

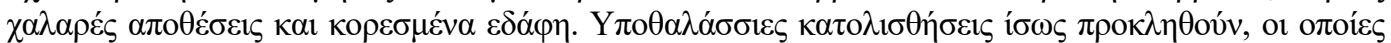

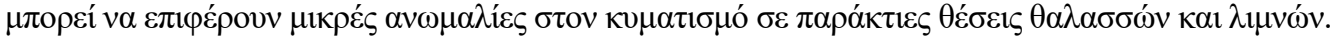

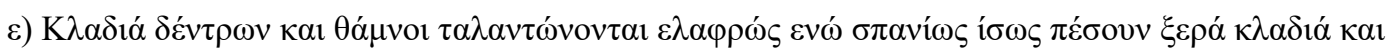

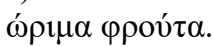

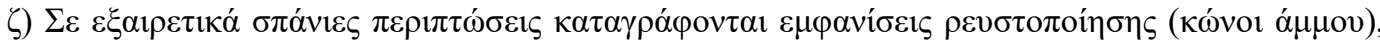

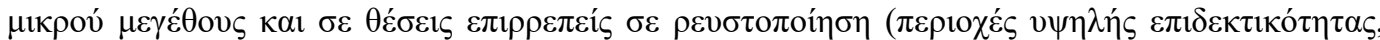

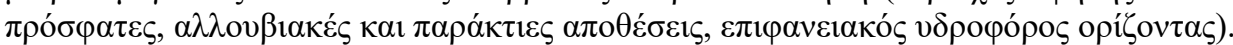

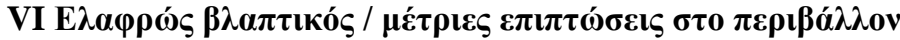

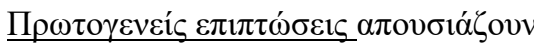

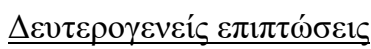

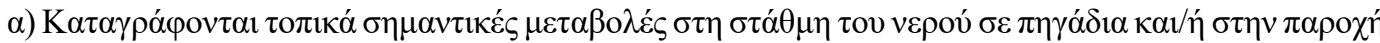

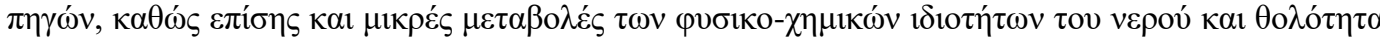

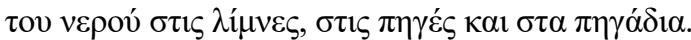

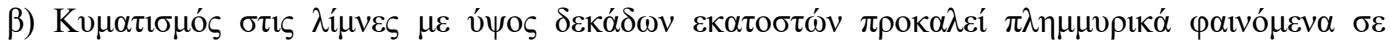

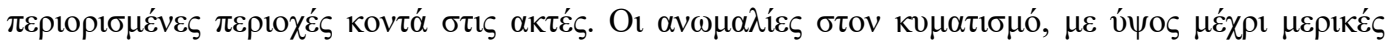

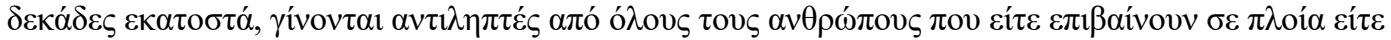

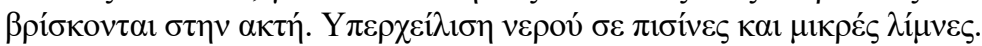

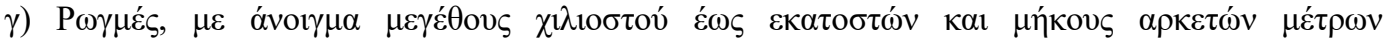

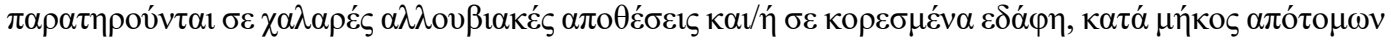

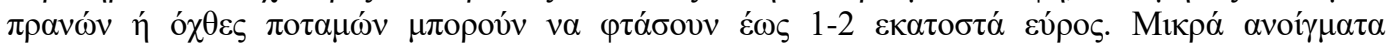

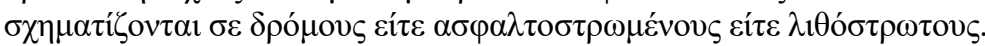

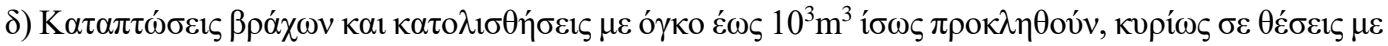

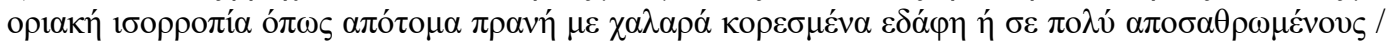

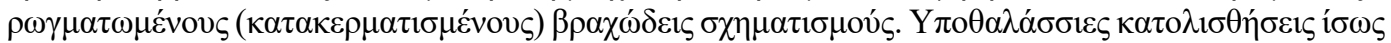

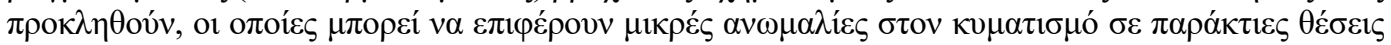

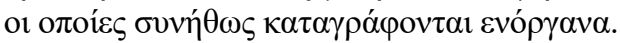

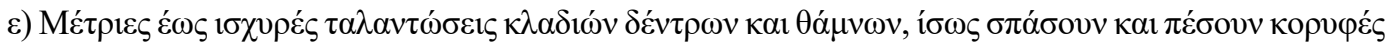

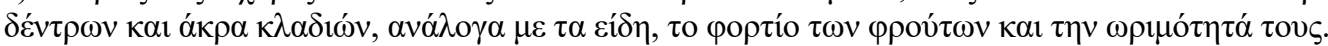

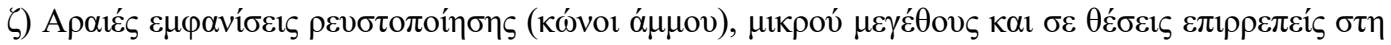

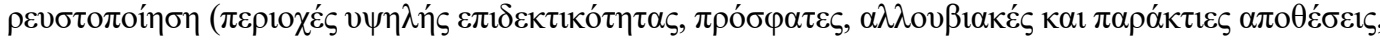

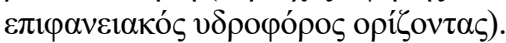




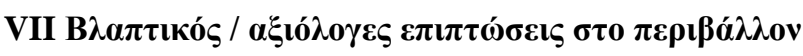

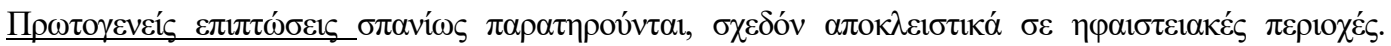

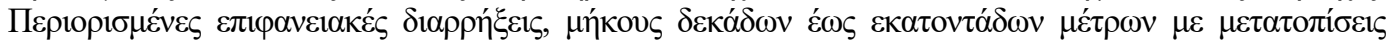

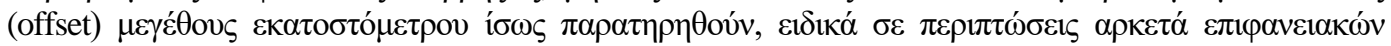

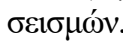

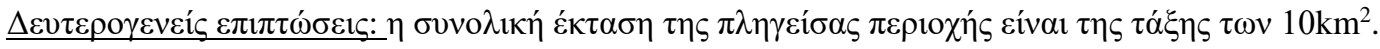

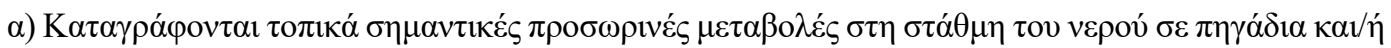

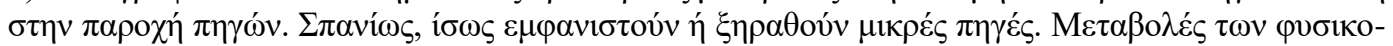
$\chi \eta \mu$

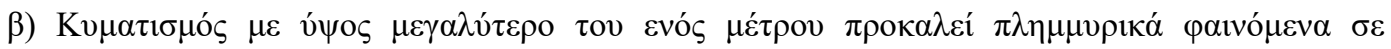

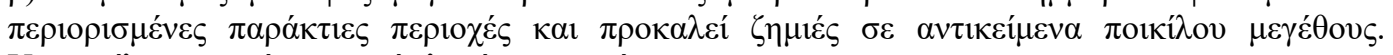

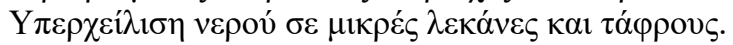

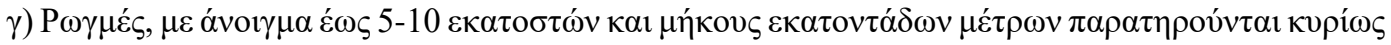

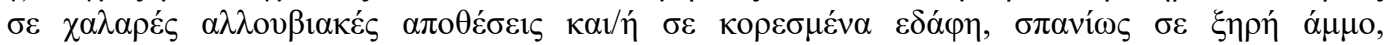

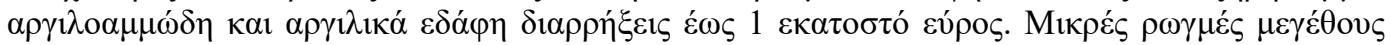

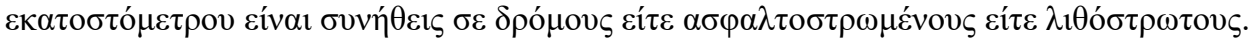

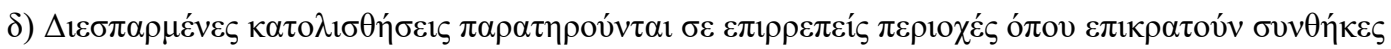

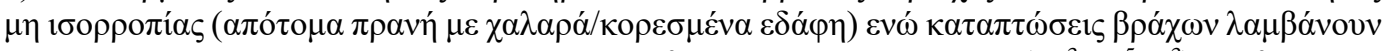

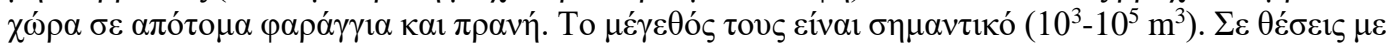

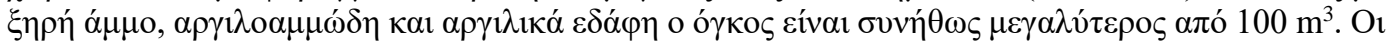

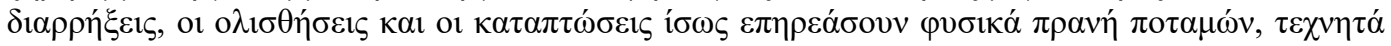

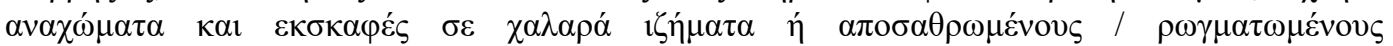

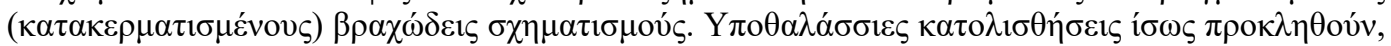

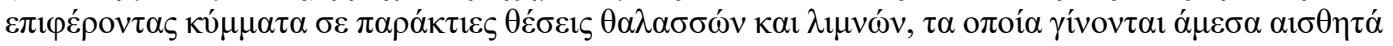

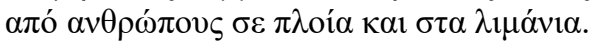

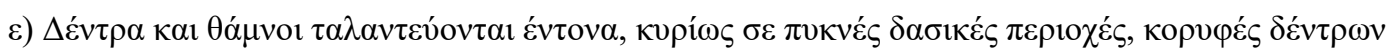

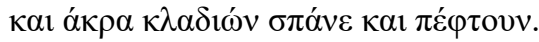

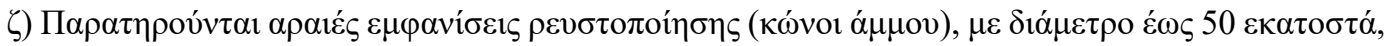

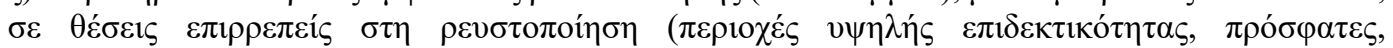

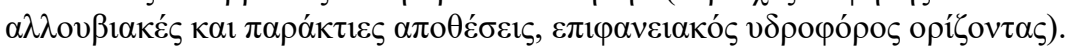

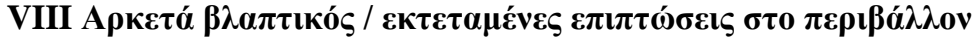

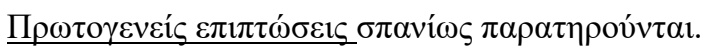

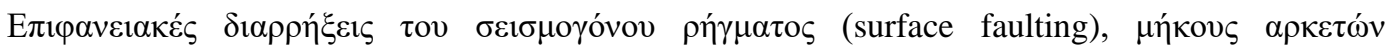

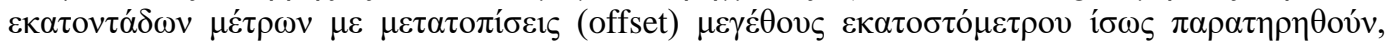

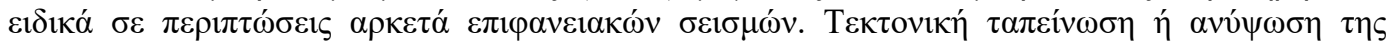

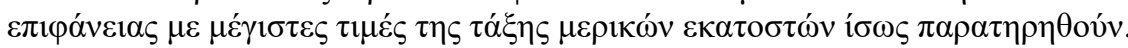

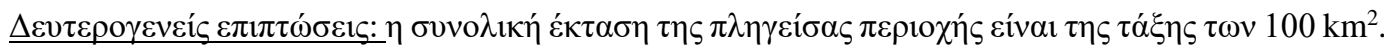

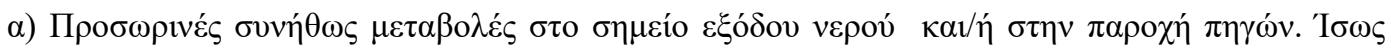

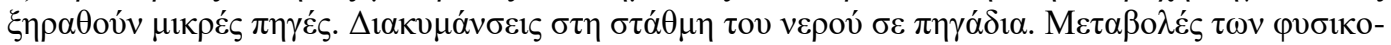

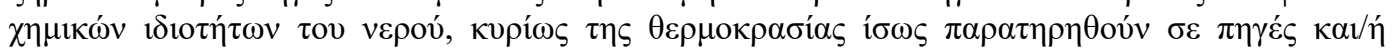

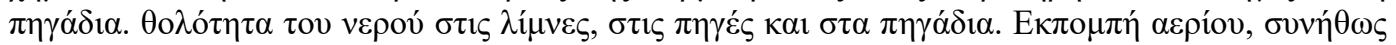

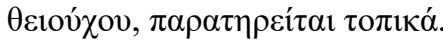

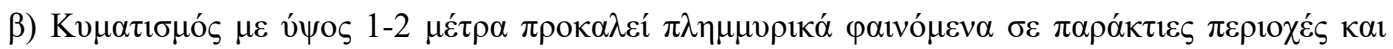

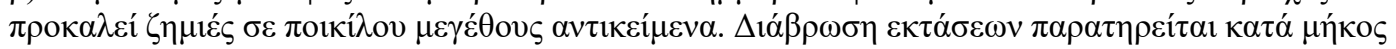




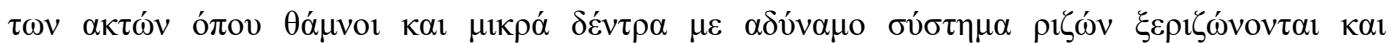

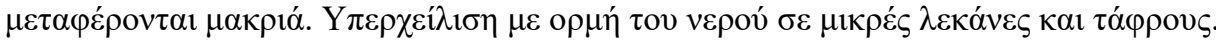

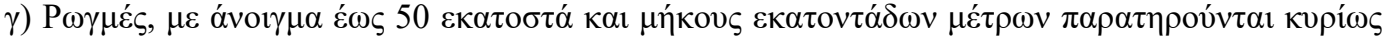

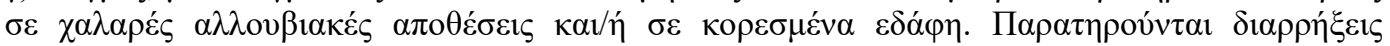

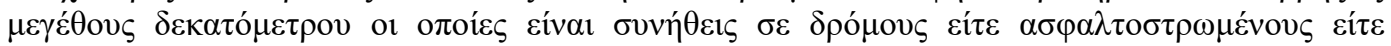

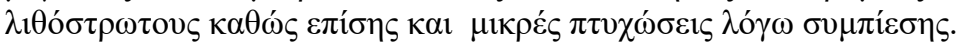

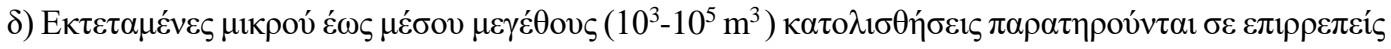

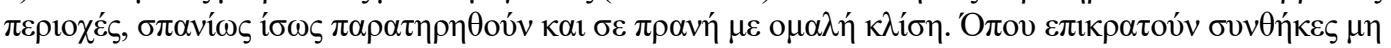

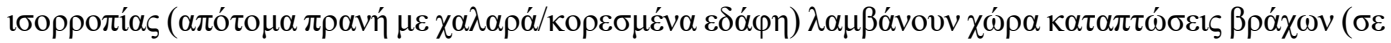

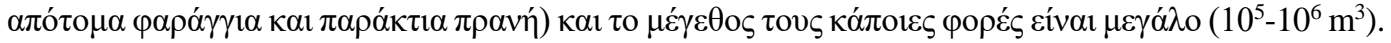

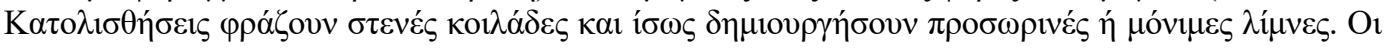

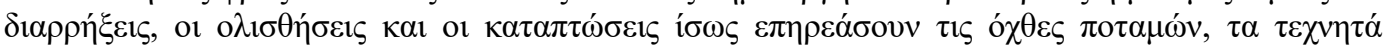

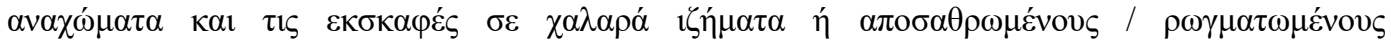

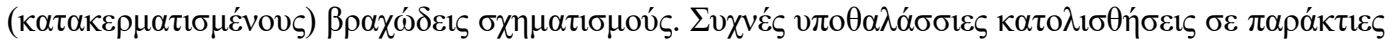
$\theta \varepsilon ́ \sigma \varepsilon 1 \zeta$.

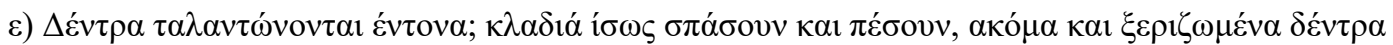
$\sigma \varepsilon \alpha \pi \delta ́ \tau o \mu \alpha \pi \rho \alpha v \eta ́$ í $\omega \varsigma \pi \varepsilon \dot{\varepsilon} \sigma o v v$.

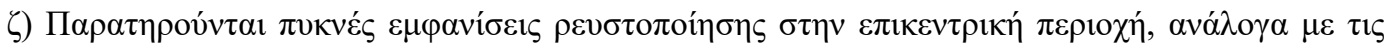

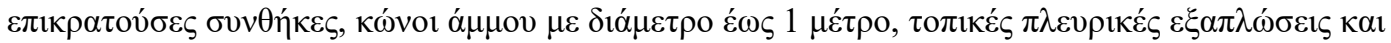

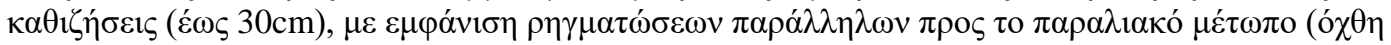

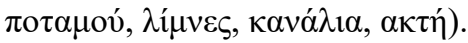

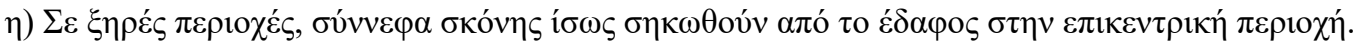

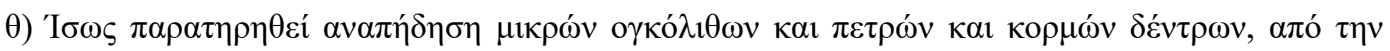

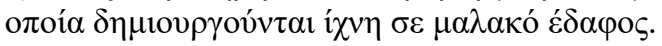

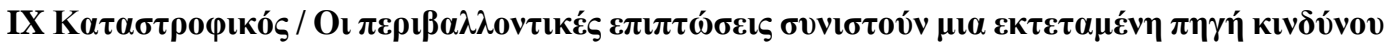

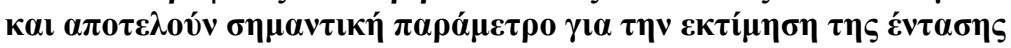

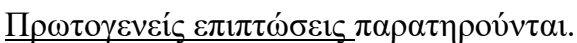

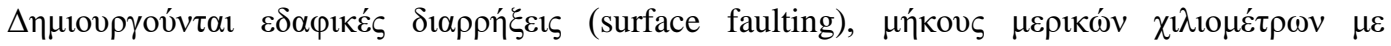

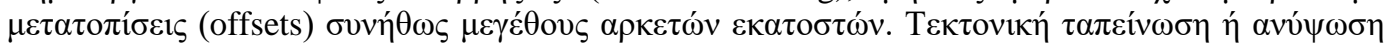

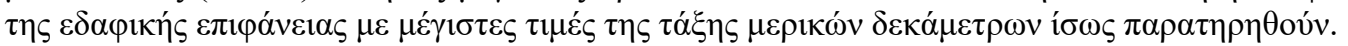

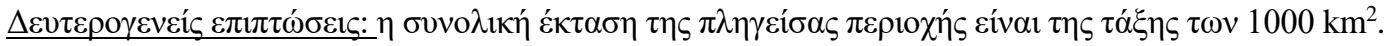

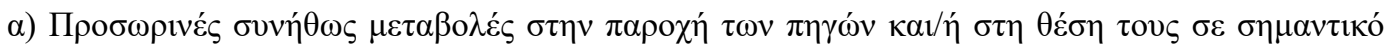

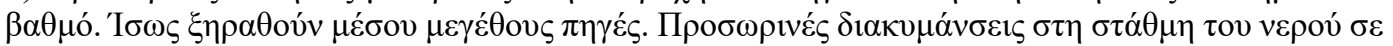

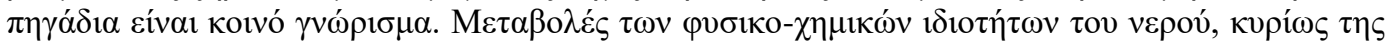

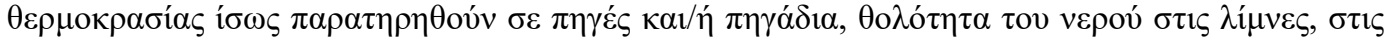

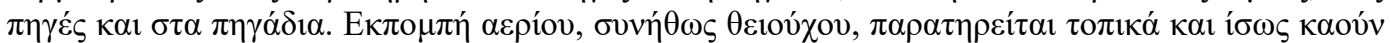

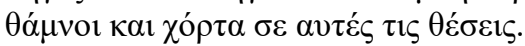

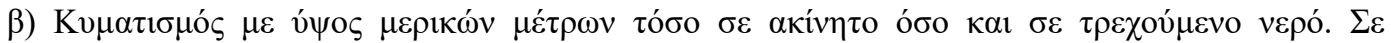

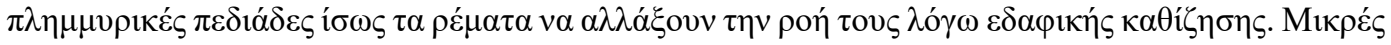

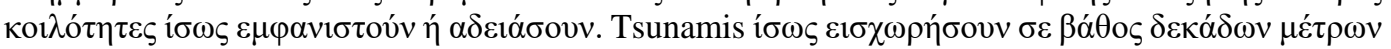

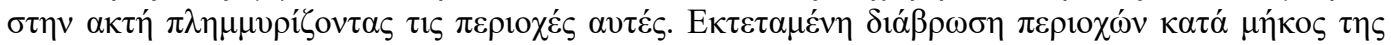

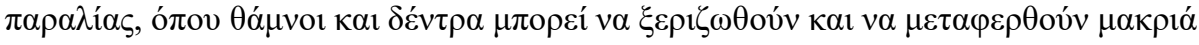

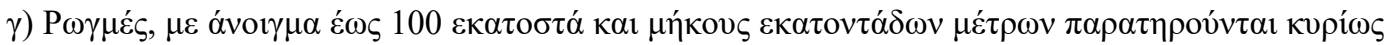

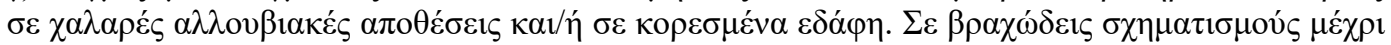

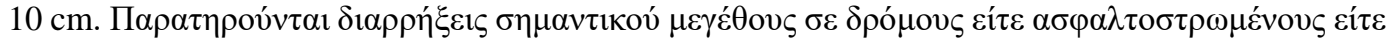

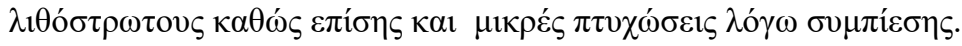




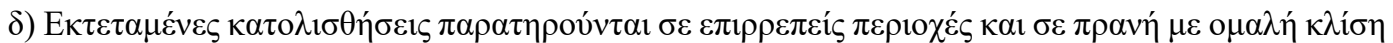

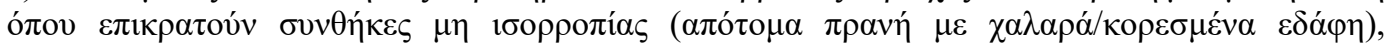

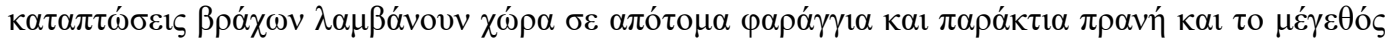

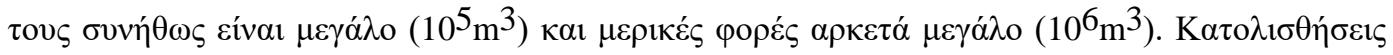

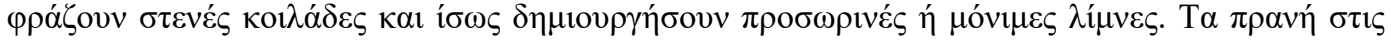

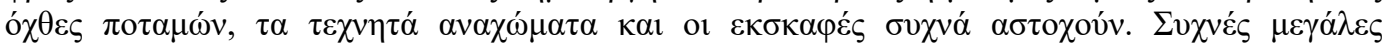

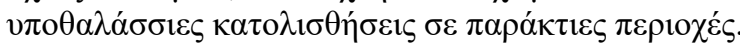

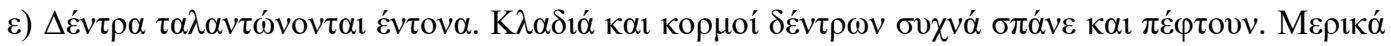

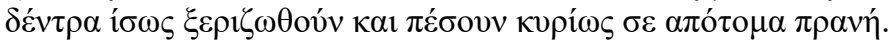

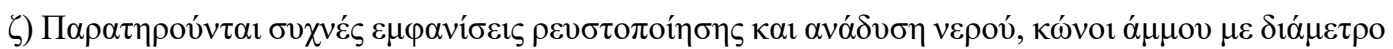

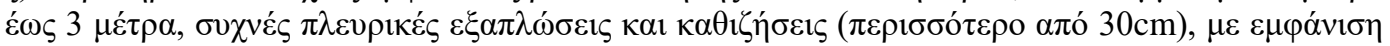

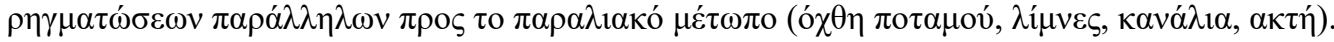

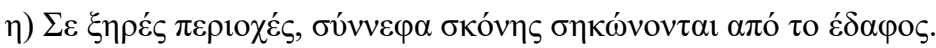

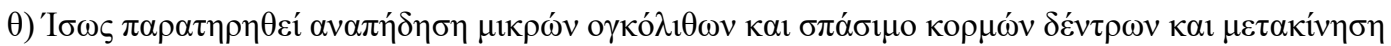

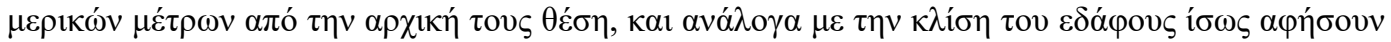

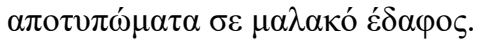

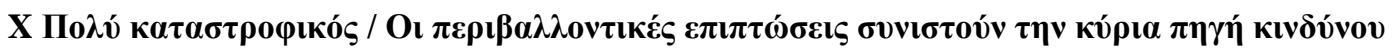

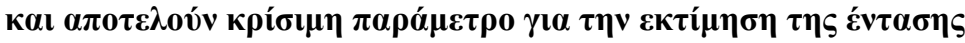

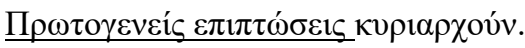

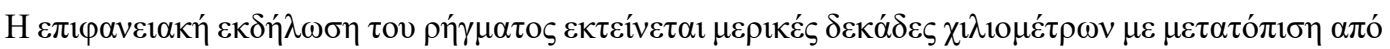

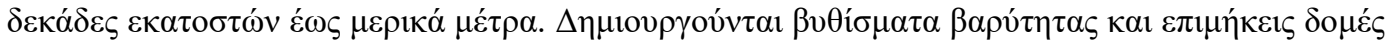

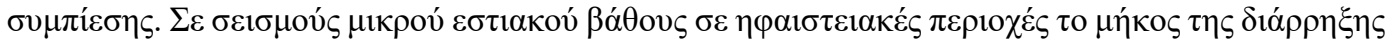

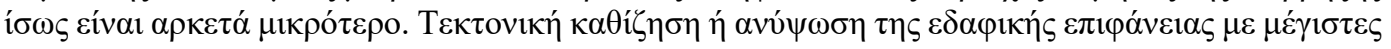

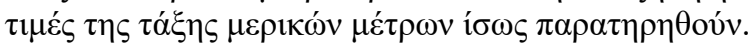

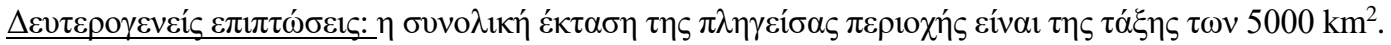

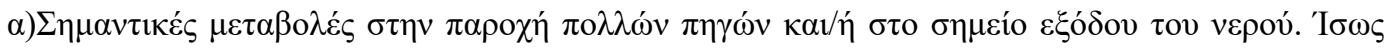

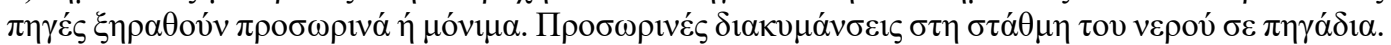

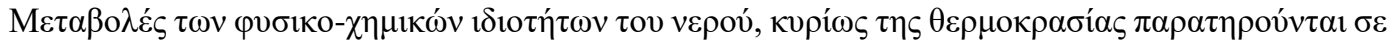

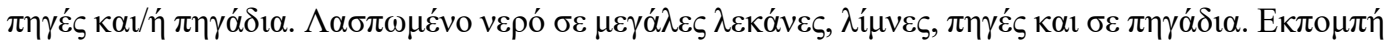

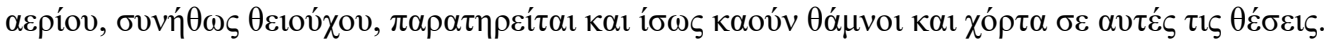

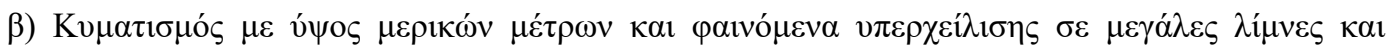

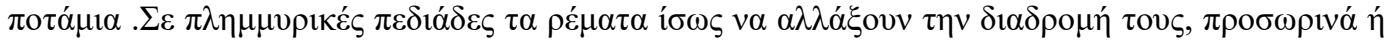

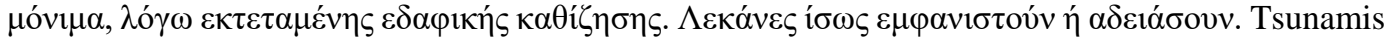

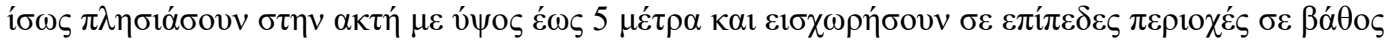

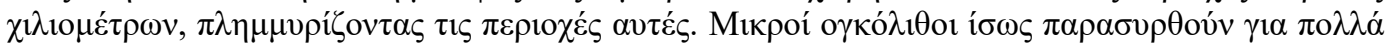

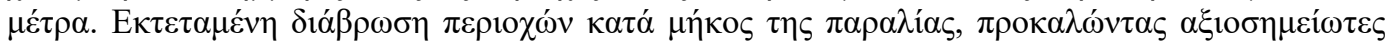

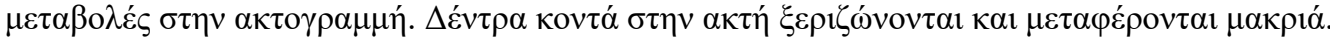

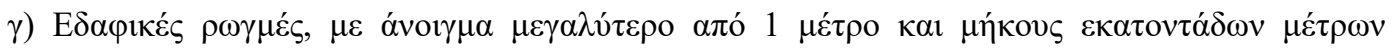

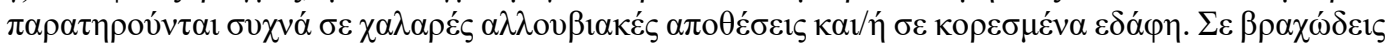

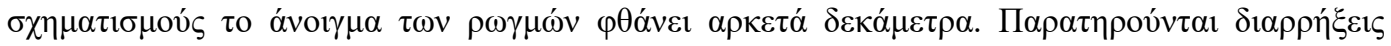

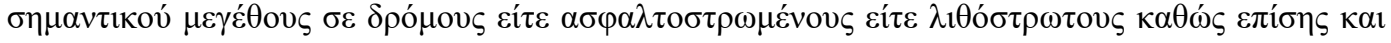

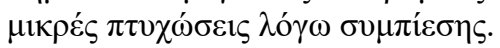

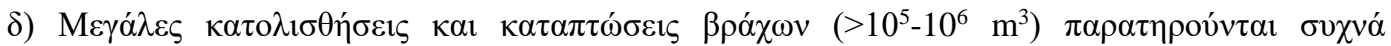

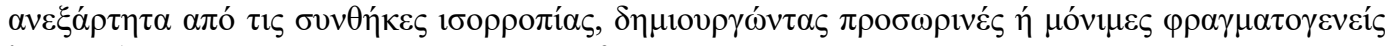

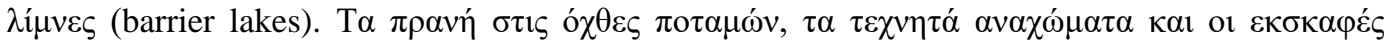

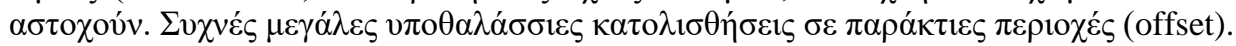




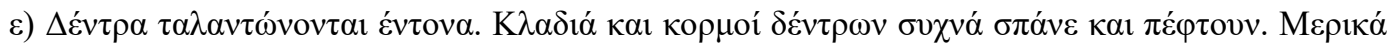

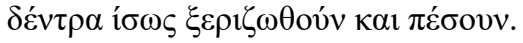

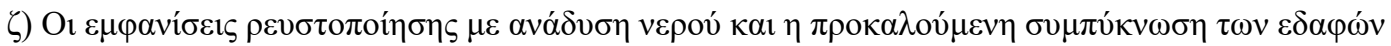

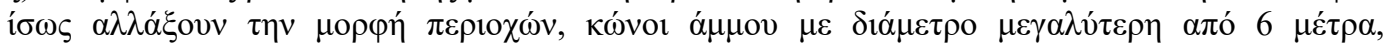

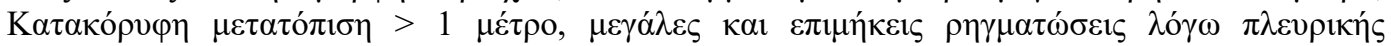

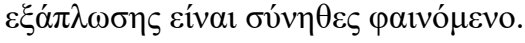

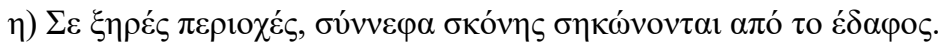

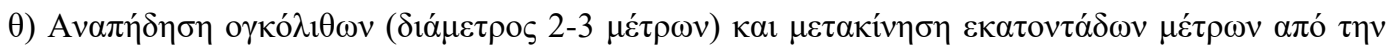

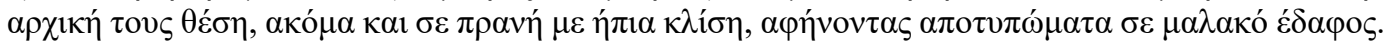

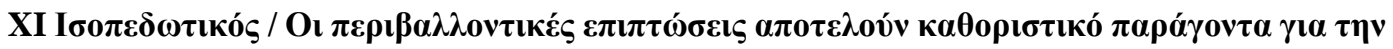

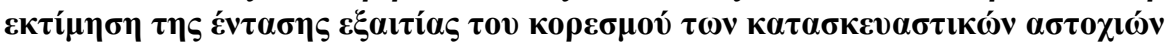

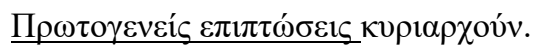

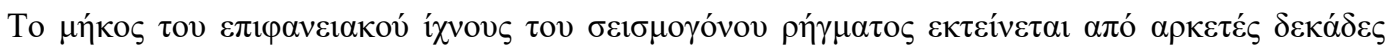

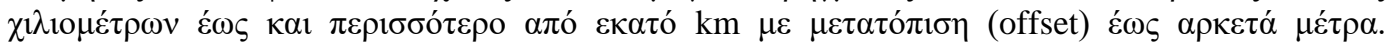

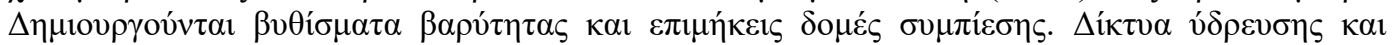

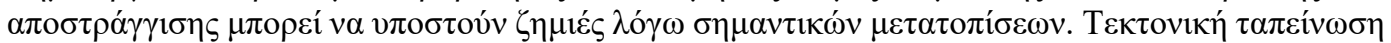

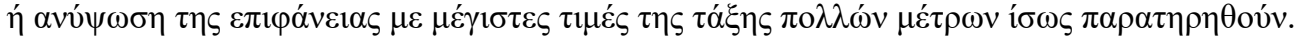

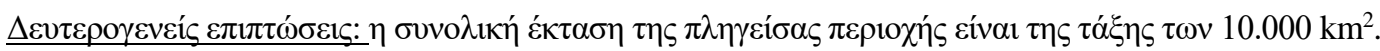

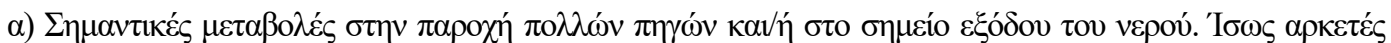

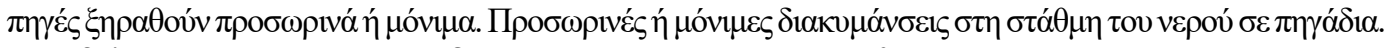

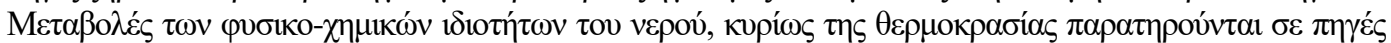

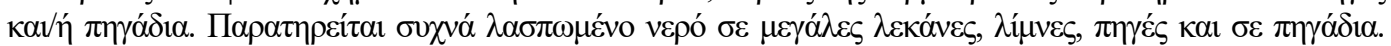

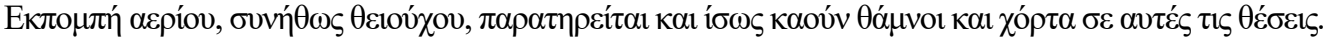

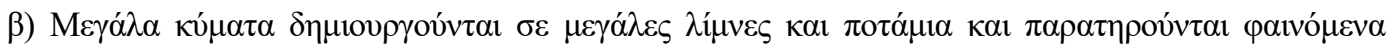

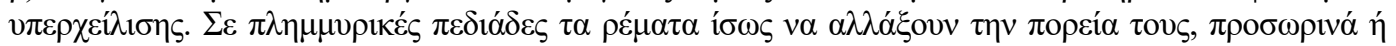

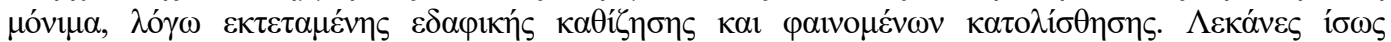

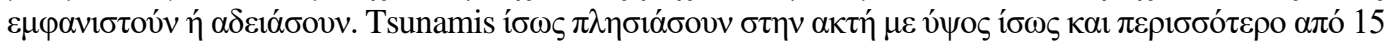

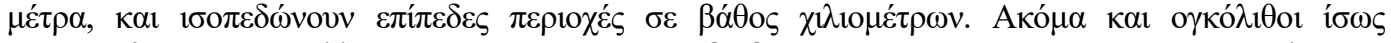

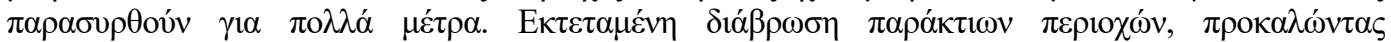

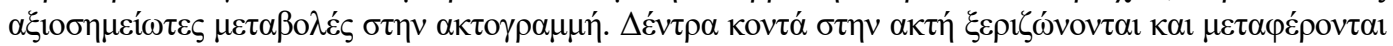

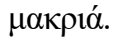

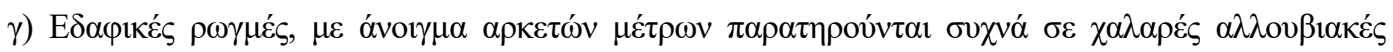

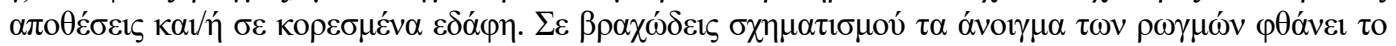

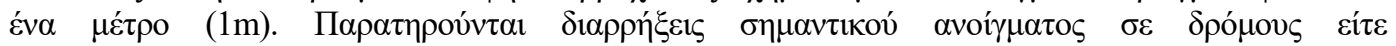

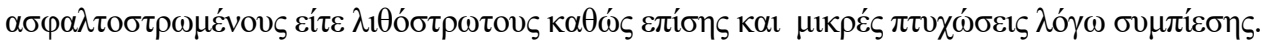

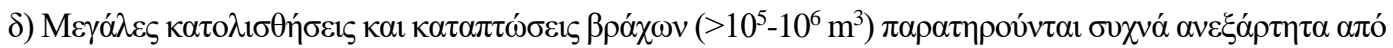

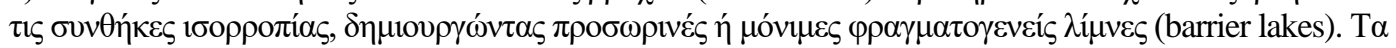

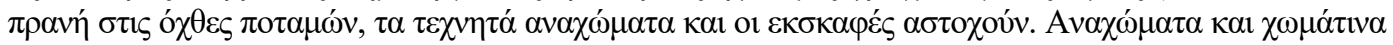

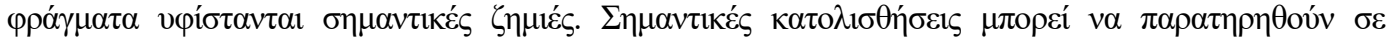

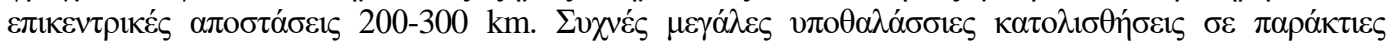
$\pi \varepsilon p 10 \chi \dot{s} s$.

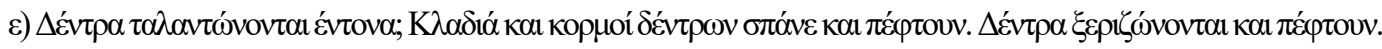

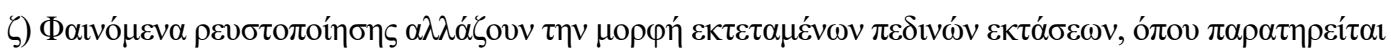

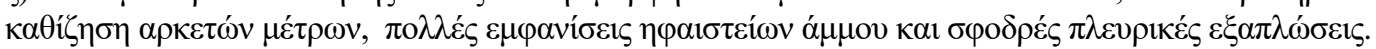

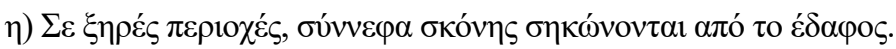




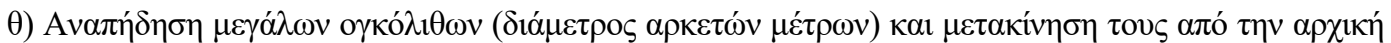

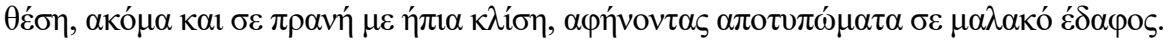

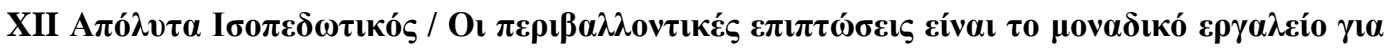

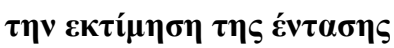

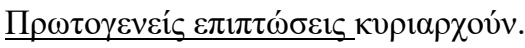

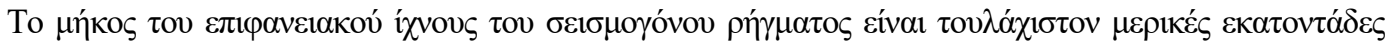

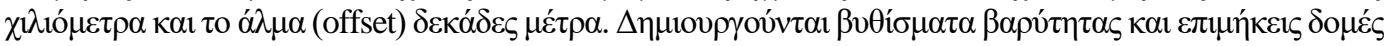

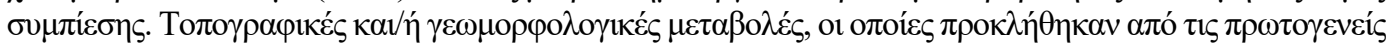

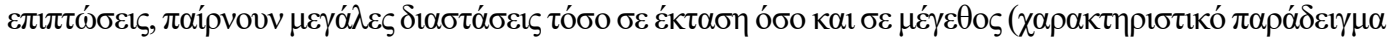

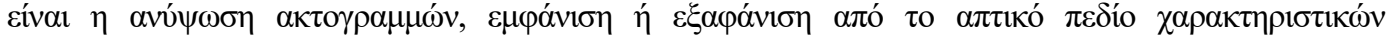

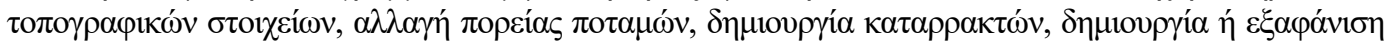

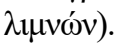

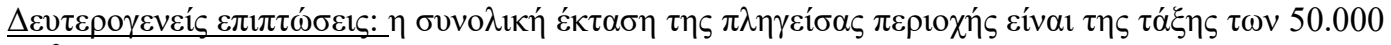
$\mathrm{km}^{2} \kappa \alpha 1 \pi \varepsilon \rho 1 \sigma \sigma o ́ \tau \varepsilon \rho o$.

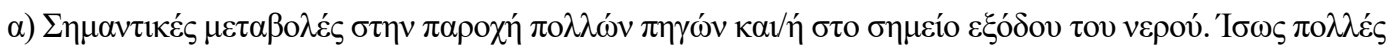

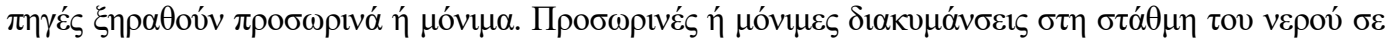

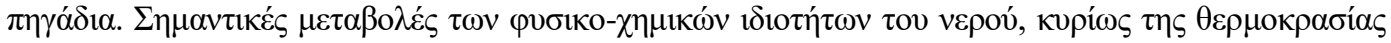

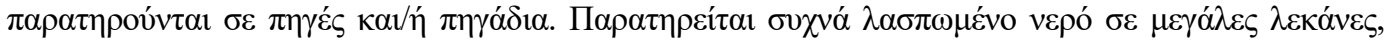

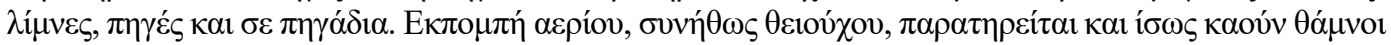

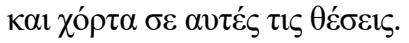

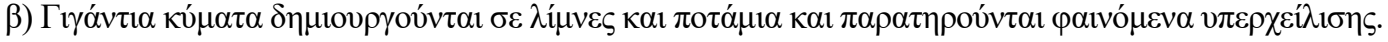

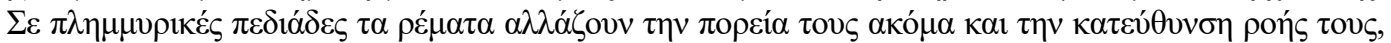

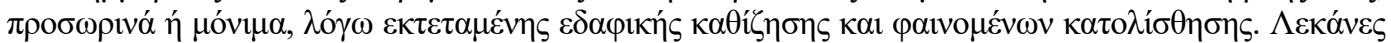

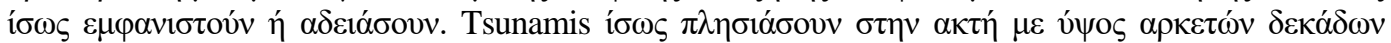

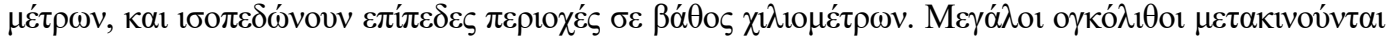

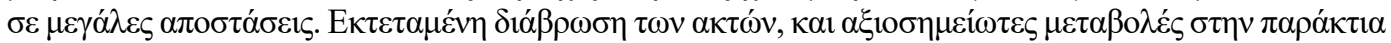

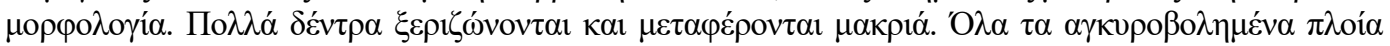

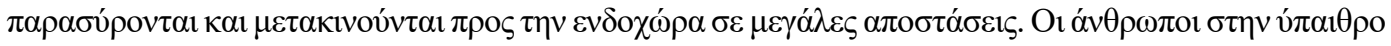

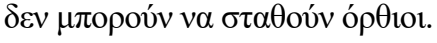

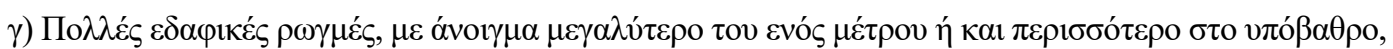

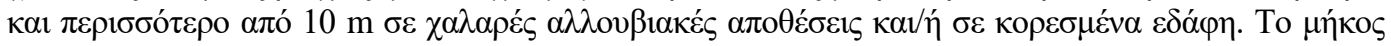

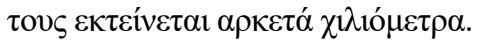

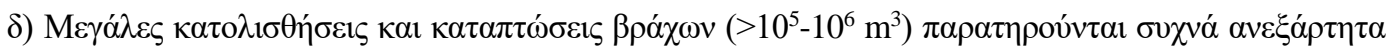

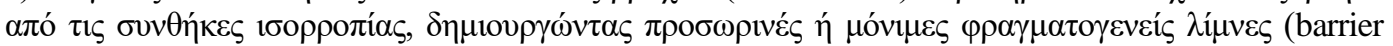

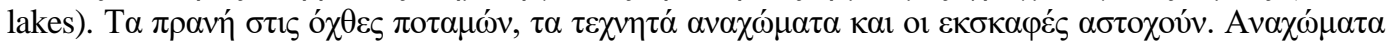

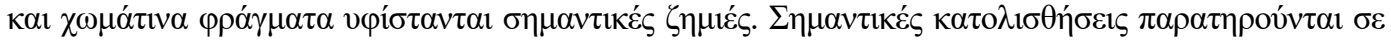
$\varepsilon \pi$

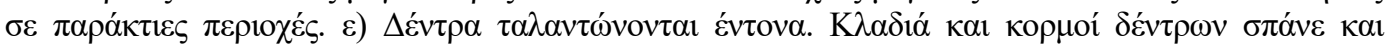

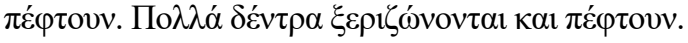

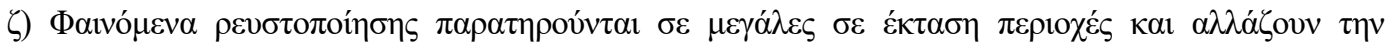

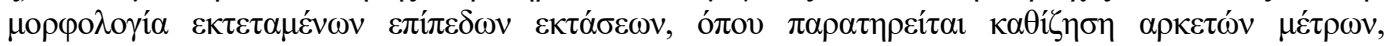

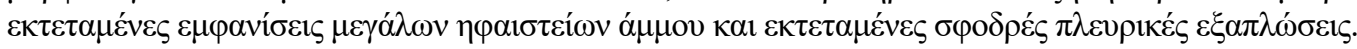

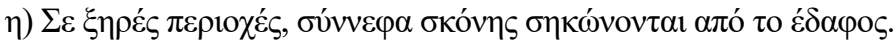

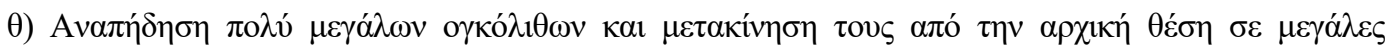

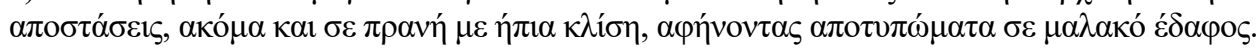

